\title{
Wireless Service Pricing under Multiple Competitive Providers and Congestion-sensitive Users
}

\author{
Andre Nel and Hailing Zhu \\ University of Johannesburg \\ South Africa
}

\section{Introduction}

With the deregulation of telecommunication industry and the fast development of broadband wireless technologies, i.e., Wireless Mesh Network (WMN), WiFi (802.11g) and WiMAX (802.16), it can be imagined that in the future users can access Internet or other wireless services, e.g., telephony, through diverse wireless service providers (WSPs) and technologies. In this complex networking landscape, moving decision-making from access points to users is a path to achieving system scalability (Zemlianov \& de Veciana, 2005). Thus, for users, it is increasingly the case that they have more freedom to choose among several WSPs who provide wireless services instead of being contractually tied to a single WSP. For example, a user wishing to access the Internet via a WiFi hotspot or access point (AP) may find him in a zone covered by several wireless access providers, or he may choose among different transmission platforms: WiFi, WiMAX, 3G, and so on. In such a market, in which multiple WSPs compete for users who are price- and congestion-sensitive, it is important to investigate the economic issues that arise due to the presence of multiple competing service providers.

In such a competitive environment, all players are self-interested in a sense that their actions or reactions in response to others' actions only focus on maximizing their own payoffs. From a WSP's point of view, it has to compete for users with other WSPs while maximizing its profit. From a user's point of view, he aims to maximize his compensated utility by choosing a WSP offering the best trade-off between quality of service (QoS) and price. Our primary goal is to understand how each WSP sets its price in the presence of price-sensitive and congestion-sensitive users and other competing WSPs to maximize its own profit. Note that we focus on the price setting problem among multiple WSPs instead of price discrimination among users. Thus we simply assume that the users are homogeneous in utility functions and willingness to pay.

According to the current design of WMN architectures, a user's requests will be routed to one AP or base station (BS) (in the IEEE802.16 standards APs of the IEEE 802.11 are called base stations) automatically so that the data flows generated by the user's requests can take the most appropriate route in terms minimum hop count or other QoS metrics (i.e., bandwidth, end-to-end delay, and so on). However, from the user's point of view, besides QoS, the price is also an important consideration when the user selects an AP or BS for wireless service delivery. It is generally accepted that the current wireless data network models are flawed in the sense that they fail to capture (Das et al., 2004): 
- The utility of the services and network from the user's perspective;

- The impact of user demands on revenue utility from the service providers perspective.

Even though the current design of architectures, algorithms and protocols for WMNs does take users' QoS requirement into account, price competition among WSPs is not taken into consideration. We believe that in the presence of competition among multiple WSPs with different prices resource distributions within the network would be affected significantly. This would in turn affect the engineering design of WMNs and other wireless delivery models. In our pricing model, we assume that users can choose a WSP's AP or BS based on the WSPs' quoted prices and the perceived QoS instead of just being directed automatically to a certain AP or BS by routing protocols.

In order to obtain a return on investment, each service provider needs a pricing strategy to charge its users for the service it offers. Pricing communication network services has been seen as a soft tool to cope with congestion, to control demand, and to induce users to use the network in a desirable way while maximizing service providers' profits. A well-designed dynamic pricing policy allows a service provider to capture the changes of users behavior and network status, and to adjust its prices based on these dynamic changes. In the case of high network utilization, the service provider increases its price, which in turn makes price-sensitive users reduce their demand as a response. Similarly, in the case of low network utilization, the service provider decreases its price to attract more users. With a proper pricing scheme, a service provider and its users are allowed to act individually to express the values that they are willing to charge or pay, and to reach an equilibrium where their individual utilities are maximized simultaneously. Furthermore, in the presence of other competing service providers, each WSP's price is dependent on other service providers' prices and network status, which affect users behavior because utility maximizing users always choose the service provider offering the best combination of price and QoS.

Game theory attempts to model the strategic interactions among self-interested players who must make choices that potentially affect other players' interests. In particular, non-cooperative game theory is primarily used as a typical modeling tool to analyze situations in which players' payoffs depend on the actions of other players. In principle, in a non-cooperative game each player makes his decision independently and attempts to get the most out of the game on the basis that the other player is not cooperating in any way. In this chapter, we discuss an oligopoly, in which multiple WSPs with asymmetric costs providing wireless services with possibly different qualities compete for a group of users through their prices, using a game-theoretical approach. Our objective is to develop a framework to analyze the interaction among multiple competing WSPs and price- and congestion-sensitive users and identify the Nash equilibrium prices.

\section{Game theory for oligopoly and its applications to communication network pricing}

Game theory aims at modeling situations in which players have to make specific moves ${ }^{1}$ that have mutual, possibly conflicting, consequences. In particular, it studies interactions among self-interested players in a way that interaction strategies can be designed to maximize the payoff of a player in a multi-player game. It also enable the development of mechanisms that have certain desirable properties. As its name suggests, the basic concepts of game theory

\footnotetext{
${ }^{1}$ In the game theory terminology, a move constitutes taking a decision that will have pre-determined consequences.
} 
arose from the study of games such as chess and checkers (Parsons et al., 2002). However, it rapidly became clear that the techniques and results of game theory can be applied to all interactions that occur between self-interested players. The classic game theoretic question asked is: what is the best or the most rational thing a player can do? In most multi-player games, the overall outcome depends critically on the choices made by all players involved. This implies that in order for a player to make a choice that optimizes his payoff, he must reason strategically. That is, the player must take into account the decisions that other players may make, and must assume that they will act rationally so as to optimize their own payoffs. Game theory provides a mathematical framework for formalizing and analyzing these situations and finding the possible results of the games.

Emerging as a tool for modeling and solving economic problems, game theory has also found its way into other domains where conflicting multiple parties have conflicting goals. Naturally, it has been used extensively for studying pricing problems for the Internet, or more generally telecommunication networks, e.g. (Altman \& Basar, 1998) (La \& Anantharam, 1999) (Altman et al., 2006) (Musacchio \& Walrand, 2006). In Internet pricing, the fundamental aspects of multi-party (Internet service providers (ISPs) and users) optimization problems can be captured by game theory. The outcomes of a game are the utilities of every players. The ISPs and the users respectively choose their best strategies (the price for the ISPs and the demand for the users for instance) to get their desired outcomes.

Normally, pricing with a game theoretic approach is related to network resource management problem. Cooperative game theory, which requires signalization or agreements among player, has been used to obtain a Nash bargaining framework to address network issues like resource allocation, network efficiency, fairness and at the same time service provider's revenue maximization and pricing (Yaïche et al., 2000). In (Dziong \& Mason, 1996), it is shown that the cooperation between two ISPs benefits both the ISPs and the users. In (La \& Anantharam, 2002), La et al. propose an algorithm in which the network providers adjust their prices and the users adjust their rates so that an optimal equilibrium is reached, while maintaining proportional fairness.

However, in a wireless service competition market with multiple competing WSPs and a set of users, all players have conflicting interests. On one hand, the WSPs' ultimate goal is to maximize their own revenues. Their attempt to maximize user's satisfaction, system utilization, etc., is merely an approach to achieve this ultimate goal. Hence, in this WSPs and users game, the revenue is modeled as the WSP's payoff. On the other hand, users want to maximize their own satisfaction with minimum expense, given that they have freedom to choose their WSPs and switch from one WSP to another. Then the user's overall satisfaction is modeled as user payoff. Since these two goals are different and even conflict with each other, there is no apparent motivation for WSPs and users to cooperate with each other to achieve a single optimal goal as suggested by cooperative game theory ${ }^{2}$.

In contrast to cooperative game theory, non-cooperative game theory is concerned with situations in which players' payoffs (utilities) depend on the actions of other players and in which the players cannot, in principle, sign binding agreements enforceable by third parties. The following sections give a brief introduction to the theory of non-cooperative games and its applications in Internet price competition games.

\footnotetext{
${ }^{2}$ Given that cooperation by the WSPs is incompatible with most regulatory frameworks, the interaction among the WSPs can also not be modeled by cooperative game theory.
} 


\subsection{Non-cooperative games in strategic form and nash equilibrium}

Non-cooperative game theory is a powerful tool for solving problems with conflicting goals. In a non-cooperative game, there are a number of players who have potentially conflicting interests, where each player has a set of strategies with associated payoff values, and makes his decision independently and attempts to obtain the best payoff without cooperating any player in any way. The outcome of the game is a set of strategies, each coming from the strategy set of an individual player, that optimizes the payoffs of all players. In the context of wireless data networks, the player are the WSPs and users. In compliance with the practice of game theory, we assume that both WSPs and users, are rational, meaning that their objectives are to maximize their payoffs (or utilities) individually.

Basically, there are two types of representations generally used to represent a game. Strategic form (or normal form) is the basic type used in studying non-cooperative games. Normally, strategic form games deal with the situation where the strategy decision of each player is made at the same time without observing the decision of the other player. On the other hand, the extensive form (also called a game tree) is a description of how a game is played over time. It is generally assumed that a single player can move based on observation of the prior choices of other players when the game is at a given stage. Generally speaking, games in extensive form deal with the situation where at least one player has partial information about other players' decision. There are two different scenarios for an extensive form game: a game of complete information is the strategic interaction when players are aware of each other's strategies or payoffs, i.e., all factors are common knowledge. In the game of incomplete information, at least one player is unaware of the payoffs or strategies of the other player.

In today's competitive communication market, it is impossible for service providers to divulge their payoffs or strategies to their rivals. In this chapter, all WSPs simultaneously and independently compute their quoted prices without the knowledge of their opponents' payoffs or strategies. Each WSP sets its own prices based on the users' response, but has no knowledge about other WSPs' prices and the users' response to other WSPs' prices in real time. Clearly, in this pricing game among multiple competing WSPs, the users' reaction to the WSPs' quoting prices and QoS is the determining factor. Therefore, this price competition game can be divided into two games:

- a game between the WSPs and users which can be expressed as a leader-follower game in strategic form with the users as the follower responding to the WSPs' prices and QoS; and

- a game among the WSPs which can be expressed as a simultaneous move game in strategic form.

A game in strategic form can be defined as $G=\left(i \in N, S_{i}, U_{i}\right)$, where $N$ is the set of players, each of whom attempts to maximize his own particular utility. $S_{i}$ represents the strategy space of player $i$, which is the set of all possible strategies of player $i$. A joint set of the strategy spaces of all players constitutes a strategy profile $s=\left\{s_{1}, s_{2}, \ldots, s_{N}\right\} . u_{i}(s)$ is payoff or utility that quantifies the outcome of game for player $i$ given the strategy profile $s$. Fig. 1 illustrates a simplest example of two-player strategic form game with each player having two strategies. In our case the players are a set of WSPs whose strategy and payoff are price and profit, respectively, and a group of homogeneous users who need to decide to choose which WSP to submit their requests based on the combination of the WSPs' offered prices and corresponding QoS, which are factors of user's utility function. Note that we have assumed that the users are homogeneous in utility function in the introduction to this chapter. We further assume that the profit function are the same for all WSPs. 


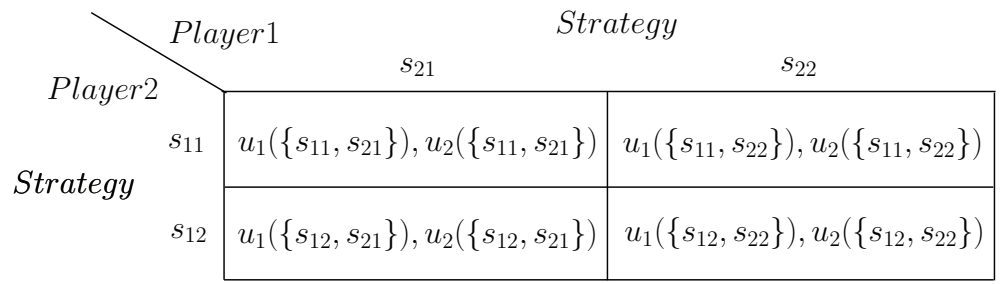

Fig. 1. A two-player game in strategic form.

To solve the game, the concept of best response needs to be introduced first. The best response of player $i$ to the profile of strategies of other players is a strategies $s_{i}^{\prime}$ such that

$$
u_{i}\left(s_{i}^{\prime}, s_{-i}\right)>u_{i}\left(s_{i}, s_{-i}\right) \quad \forall s_{-i} \in S_{-i},
$$

where subscript $-i$ represents all the players except player $i$ himself. If all players' strategies are mutual best responses to each other, then no player would have a reason to deviate from the given strategy profile. The situation in which no players has incentive to unilaterally changing his current strategy is called a Nash equilibrium. Mathematically, a Nash equilibrium is a strategy profile $s^{*}=\left\{s_{1}^{*}, s_{2}^{*} \ldots, s_{N}^{*}\right\}$ such that for each player $i$

$$
u_{i}\left(s_{i}^{*}, s_{-i^{*}}\right) \geq u_{i}\left(s_{i}, s_{-i}^{*}\right) \quad \forall s_{i} \in S_{i} .
$$

In a Nash equilibrium, none of the players can gain by unilateral deviation, which implies that no single player can leave this point without the cooperation of others in order to improve his own utility. In other words, a Nash equilibrium is a strategy profile comprised of mutual best responses of all the players ${ }^{3}$.

\subsection{Price and QoS competition in telecommunication networks}

Pricing has been seen as a soft tool to control demand, to cope with congestion and to deal with heterogeneous applications with different QoS requirements. Therefore, there has been an increased research interest in telecommunication network pricing, which leads to many proposals for new pricing schemes motivated by different objectives, e.g. to allocate scarce network resources efficiently in order to maximize social welfare, i.e. (Kelly et al., 1998) (Low \& Lapsley, 1999) (Yaïche et al., 2000) (Tassiulas et al., 2001) (La \& Anantharam, 2002) (Shu \& Varaiya, 2003) (Qiu \& Marbach, 2003), to maximize service provider's revenue, i.e. (Basar \& Srikant, 2002) (M. Bouhtou \& Wynter, 2003), to guarantee fairness among users, i.e. (Kelly et al., 1998) (Kelly, 2000), to satisfy QoS requirements for differentiated network services (La \& Anantharam, 1999) (Wang \& Schulzrinne, 1999) (Mandjes, 2003). With the rapid growth of wireless data networks, e.g. wireless ad hoc networks and wireless mesh networks, recently many price-based resource allocation schemes also have been propose for wireless data networks, i.e. (Xue et al., 2003) (Das et al., 2004) (Xue et al., 2006) (Lüthi et al., 2006) (Kao \& Huan, 2008). Pricing has also been used as an incentive mechanism to stimulate participation and collaboration of self-interested wireless node in wireless mesh networks, i.e. (Lam et al., 2006) (Lam et al., 2007).

A very large proportion of these proposed pricing schemes focus on the monopolistic case, where there is only one service provider dealing with a multitude of users and the the

\footnotetext{
${ }^{3}$ It should be noted that even though the Nash equilibrium indicates an equilibrium solution it may not be a solution that maximize the social welfare.
} 
service provider is big enough to affect the entire market. However, as telecommunication networks have progressively switched from a monopolistic network to a oligopolistic one with competitive service providers, more attention has been given to price competition among service providers, see for example, (Gibbens et al., 2000) (Cao et al., 2002) (Sakurai et al., 2003) (Armony \& Haviv, 2003) (Ros \& Tuffin, 2004) (Khan, 2005) (Zhang et al., 2008).

In practice, markets are often partly regulated and partly competitive. In the rest of this chapter, we only discuss pricing game under perfect competition in a market without regulation, in which all service providers have certain market force and there is no provider so dominant that one of them can control the price. Therefore, no one is the leader and no one is the follower in such a price competition game. As a consequence, all service providers' prices are determined by the market in which users have the ability to switch from one service provider to another. The basic assumptions of the price competition game are that both service providers play the role of rational decision makers and each service provider knows that the opponents are also rational. A rational service provider always attempts to select the best response strategy.

In the rest of this section we will introduce some proposed pricing schemes reported in literature, which are related the pricing model presented in the next sections.

In (Gibbens et al., 2000), Gibbens et al. develop a framework to analyze competition between two ISPs, either or both of which may choose to offer multiple service classes. In their analytic framework, there are two ISPs: ISP1 and ISP2 charging prices $p_{1}$ and $p_{2}$ per unit time respectively. On joining ISPi, a user receives utility $U_{i}(\theta)$ per unit time. Utility $U_{i}(\theta)$ has three components: a positive benefit $V$ which is independent of which ISP he/she joins; a dis-benefit which is a function of the degree of congestion on the network of the ISP $i K_{i}$ and the user's preference for congestion $\theta$; and a dis-benefit from having to pay a price $p_{i}$ per unit time to ISP $i$ for its service. To describe the range of preferences in the population of users in the simplest manner, assume that there is a continuum of users whose $\theta$ parameters form a population distribution which is uniformly distributed on the interval $[0,1]$. Thus the utility of a user with preference $\theta$ from joining ISP $i$ is defined as

$$
U_{i}(\theta)=V-\theta K_{i}-p_{i}
$$

For analytical simplicity, congestion on a network is defined as the number of users, $Q_{i}$, divided by the capacity of the network, $C_{i}: K_{i}=\frac{Q_{i}}{C_{i}}$. Based on these assumptions, Gibbens et al. analyze the duopoly price competition for packet-based networks and show that the unique equilibrium outcome for both networks is to offer a single service class and charge the same price.

Sakurai et al. (Sakurai et al., 2003) propose an extended model based on Gibbens et al.'s game theoretic model for the case in which an opt-out strategy is introduced for users. In their model, the users have three strategy options: joining one of the ISPs and opting out of both of them. In (Sakurai et al., 2003) it is assumed that ISP1's price is higher than ISP2's price, $p_{1}>p_{2}$, and both ISPs have the same fixed capacities $C_{1}=C_{2}=C$. A strategy for a user is a choice of ISP to join or opting out of both ISPs, given the prices quoted by the ISPs. If the user is indifferent between the two ISPs, his choice can be made randomly. Sakurai et al. suggest only the users who don't like congestion nor higher price opt out of ISP1, or mathematically only the users whose utility $U_{1}(\theta)<0(0 \leq \theta \leq 1)$ choose opting-out. Therefore, there are two types of marginal users as shown in Fig. 2: one is the users with congestion preference $\theta_{21}$, who are indifferent between joining ISP2's lower priced network and joining ISP1's higher priced network; and the other one is the users with congestion preference $\theta_{10}$, who are indifferent 


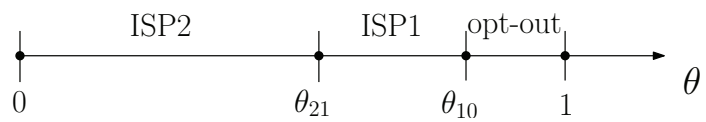

Fig. 2. Critical values of $\theta_{21}$ and $\theta_{10}$ for user preference (Sakurai et al., 2003)

between joining ISP1's higher priced network and opting out of ISP1. If there are $N$ users in the market, the numbers of users who join ISP1 and ISP2 are given by $Q_{1}=N\left(\theta_{10}-\theta_{21}\right)$ and $Q_{2}=N \theta_{21}$ respectively, provided that $0<\theta_{21}<\theta_{10}$. Sakurai et al. conclude that Nash equilibrium for this non-cooperative game model greatly depends on three factors: the user's benefit from using the Internet, $V$, ISP's network capacity, $C$, and the number of users in market, $N$.

Notice that the fundamental of both models presented by Gibbens et al. and Sakurai et al. is to find the critical values of $\theta^{*}$ determined by the indifference relation $U_{1}\left(\theta^{*}\right)=U_{2}\left(\theta^{*}\right)$. The philosophy behind this is that when the user's utilities for joining either ISP are equal two ISPs can reach a Nash equilibrium, in which each ISP's pricing strategy is optimal in the sense that one ISP has no incentive to change its price strategy in response to the other ISP's strategy and vice versa. Because the users are indifferent between joining ISP1 or joining ISP2 when the utilities for joining either ISP are the same, no user of one ISP has an incentive to switch to the other ISP and all the users will stay where they are. This means that both ISP have no incentive to deviate from their current strategies. Indeed, if the users's compensated utility with ISP1 is lower than the one with ISP2 and both are positive, the users would switch to ISP2 until the compensated utility with ISP2 reaches the one with ISP1.

In fact, this philosophy is related to pricing in the presence of delay cost, which has received increasing interest in study of price competition among providers in communication network research literature. In (Ros \& Tuffin, 2004), Ros et al. propose a mathematical model involving delay cost for a Paris Metro Pricing (PMP) network, where there are $I$ classes and for the class $i$ per packet price is $p_{i}$. In their analytical framework, a total cost function $p_{i}+\gamma d_{i}$ is associated to a class $i$, where $d_{i}$ is the mean delay for a packet in the network and $\gamma$ is a constant converting delay into money. A packet associated with a utility measure $U$, which is assumed to follow the same distribution for every packet, enters network $i$ if

$$
i=\min _{j \in I} p_{j}+\gamma d_{j} \quad \text { and } \quad U \geq p_{i}+\gamma d_{i} .
$$

That means that the packet chooses the least expensive subnetwork in terms of total cost. If $U<\min _{j \in I} p_{j}+\gamma d_{j}$, the packet does not enter at all, meaning that the network is too expensive for it. In equilibrium, the distribution of packets among classes has to be stable, meaning that the total cost $p_{j}+\gamma d_{j}$ is the same for all classes $j$. If for a given class $j$ the value $p_{j}+\gamma d_{j}$ were smaller than the total cost of the other classes, then new packets entering the network would choose class $j$ until its total cost reaches that of other classes. This corresponds to a Wardrop equilibrium (Altman \& Wynter, 2002) which can be described as: demand is distributed in such a way that all users choose one of the cheapest providers. Even though the aim of Ros et al.'s model is to analyze the so-called PMP scheme which separates the network into different and independent subnetworks, the analytical framework can be extended to analyze multi-providers competition, because each subnetwork in their model behaves equivalently and the customers (data packets) choose their subnetwork taking into account the prices and the QoS offered by different subnetwork, which are in common with the multi-providers competition. 
Duopoly competition in the presence of a delay cost has also been studied by Armony et al. (Armony \& Haviv, 2003). They analyze the price competition between two firms offering identical services under the assumption that all customers, belonging to one of two classes and differing by their waiting cost parameters, value the received service identically. Note that each type of customers, $H$-customers and $L$-customers, has its own waiting cost parameter, defined as the cost a customer incurs per unit of waiting time. Besides the choice between the two firms, the customers also have an option of balking, which is not included in Ros et al.'s work (Ros \& Tuffin, 2004). The expected utility of a customer with a cost parameter $C(C=L, H)$ who joins firm $i$ is $R-p_{i}-C W_{i}$, where $R$ is customers' value for receiving service, $p_{i}$ is the price charged by firm $i$ and $W_{i}$ is the expected waiting time (reponse time) determined using a $\mathrm{M} / \mathrm{M} / 1$ queue. The corresponding utility associated with balking is assumed to be zero ${ }^{4}$. In their analysis, customers use mixed equilibrium strategies that specify the probability with which the customers choose each one of the firms given any pair of prices while firms use pure strategies in choosing what prices to charge per customer.

In (Zhang et al., 2008), a pricing competition model for packet-switching networks with a QoS guarantee in terms of an expected per-packet delay is studied. Zhang et al. propose a general framework in which service providers offering multi-class priority-based services compete to maximize their profits, while satisfying the expected delay guarantee in each class. The customer is assumed to have to choose a class of service from a service provider based on their preference for the guaranteed delay announced by the service providers. Zhang et al.'s work is also related to pricing in the presence of delay cost, which is assumed to be a linear function of the delay sensitivity $h, \gamma h$, where $\gamma$ is a constant and $h$ is uniformly distributed between $[0,1]$. Then the expected net benefit to a user with $(v, h)$ for sending a message in class $i$ from provider $j$ is $v-p_{i, j}-\gamma h d_{i}$, where, $v$ is user's value assigned to the transmission of each packet in a message, and $d_{i}$ is the expected per-packet delay guarantee, which is determined using $M^{x} / G / 1 / \operatorname{Pr}$ queuing theory results. The benefit to the user for not choosing any service is zero. Two cases are studied in (Zhang et al., 2008): the case of fixed delay guarantee and the case that providers compete in both delay guarantee and price. For both cases, it is found that equilibrium outcome is symmetric $\left(p_{1}=p_{2}\right)$.

\section{A duopoly pricing model for wireless data networks under congestion-sensitive users}

In this section, we present the basic model, which has been presented in (Zhu et al., 2009), for the pricing game under two WSPs competition based on the works of (Gibbens et al., 2000) and (Sakurai et al., 2003), which addresses the question of duopoly with demand-dependent quality. In this pricing game, the players are:

1. two WSPs: $\mathrm{WSP}_{1}$ and $\mathrm{WSP}_{2}$, who compete to maximize their individual profits in a market;

2. a group of homogeneous users who are price-as well as congestion-sensitive.

For analytical convenience, we assume that both WSPs' capacities are fixed and equal so that the only strategy for the WSPs is related to setting its price. We focus on the pricing strategies of the WSPs and analyze a Nash equilibrium for this two WSPs competition with regard to their pricing strategies. Given the prices and QoS offered by the WSPs, a strategy for a user is a choice of which WSP to join or opting out of both WSPs.

\footnotetext{
${ }^{4}$ This excludes the very real situation where the utility of balking is actually negative.
} 


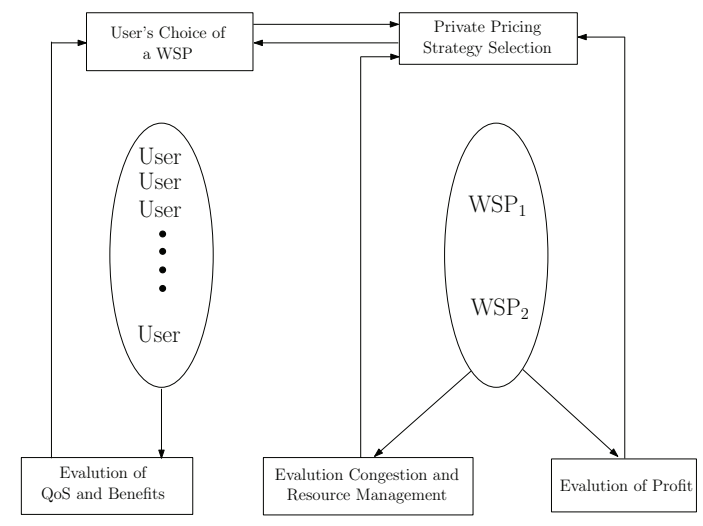

Fig. 3. Pricing model for two WSPs

\subsection{Basic model}

We model this oligopoly as a two-stage non-cooperative game: first, in stage 1, both WSPs set their prices to maximize their profits respectively. Then, in stage 2 , given prices quoted by both WSPs and their QoS, the users decide whether purchase the service, and if so, from which WSP. Note that the two stages are solved sequentially. Given prices quoted by the WSPs and perceived QoS, the users decide in Stage 2 to choose which WSP. Based on the decisions of the users, in Stage 1 the WSPs adjust their optimal prices. This sequential decision-making process is illustrated in Fig. 3.

Suppose there are two WSPs: $\mathrm{WSP}_{1}$ and $\mathrm{WSP}_{2}$ in a market competing to maximize their individual profits. Assume $\mathrm{WSP}_{1}$ and $\mathrm{WSP}_{2}$ set prices $p_{1}$ and $p_{2}$ respectively per packet transmission, and the costs for providing per packet transmission are $c_{1}$ and $c_{2}$ respectively. Let the profit of $\mathrm{WSP}_{1}$ and $\mathrm{WSP}_{2}$ be denoted as $\Pi_{1}$ and $\Pi_{2}$ respectively. Obviously, $\Pi_{i}$ is a function of the price charged per packet, $p_{i}$, and the $\mathrm{WSP}_{i}{ }^{\prime}$ s cost, $c_{i}$.

In this duopoly, both WSPs are able to change their prices based on their congestion status while the price- and congestion-sensitive users who are connecting to one WSP are able to switch to WSP anytime they want. In other words, the users' association with the WSPs would be on a per-service or per-session basis. However, each WSP only knows its own quoting prices, it own cost and the users response to its quoting price, and has no knowledge about its rival's price, cost and the users response to its rival's price in real time. It is a realistic assumption because it is not allowed for a WSP to divulge its private information to its rivals. Therefore, the users' reaction to the multiple WSPs' prices and QoS is the determining factor in this two WSPs' price competition game.

Assume the behavior of all users are identical and economically rational, so we can view all the requests as being from the same user and simply use the singular word "user". On joining $\mathrm{WSP}_{i}(i=1,2)$, a user receives gross utility $U_{i}$. Consider each WSP as a system that can only serve a finite population of potential users, meaning that the gross utility that the user obtains when subscribing to one WSP depends partly on the level of congestion or QoS of the WSP. Obviously, generally speaking, the larger the number of users subscribe to a WSP, the lower the gross utility the users can obtain because the level of congestion increases as users join. However, QoS may take many different forms, such as response time, bit-error rate, packet delay, and so forth. For the purpose of facilitating analysis, mean packet delay (or response time), $E D$, is used to determine the utility experienced by a user in this chapter. Clearly, the 
mean packet delay is affected by the number of users who subscribe to the same WSP.

A strategy for the user has three options: subscribing to $\mathrm{WSP}_{1}$; subscribing to $\mathrm{WSP}_{2}$; opting out of both of them. To define the strategy of the user mathematically, we have to introduce the concept of compensated utility, which is gross utility minus price. As defined in (Mandjes, 2003) without loss of generality, the compensated utility curves can be defined as:

$$
\mathbb{U}(E D)=U(E D)-p \quad \text { with } U(E D)=E D^{-\theta},
$$

where $U(\cdot)$ is gross utility and $\theta>0$. To simplify the calculation, we choose $\theta=1$. Thus, the user's gross utility $U(E D)=1 / E D$ and the compensated utility $\mathbb{U}(\mathbb{E D})=1 / E D-p$. Note that $U(E D)$ monotonically decreases with its argument $E D$.

The user wants to use the service as long as his compensated utility is positive. If the compensated utilities that the user receives from both WSPs are negative, the user will choose to submit neither of them. Then, if the compensated utilities that a user receives from one WSP or both of them are positive, the user will choose the WSP from which he receives the higher compensated utility. In other words, the user's strategy strongly depends on the price difference and the QoS performance difference between these two WSPs.

Suppose that mean packet delays for $\mathrm{WSP}_{1}$ and $\mathrm{WSP}_{2}$ are $E D_{1}$ and $E D_{2}$ respectively. Denote $U_{1}\left(E D_{1}\right)$ and $U_{2}\left(E D_{2}\right)$ as the user's gross utility for $W_{S P}$ and $W_{S P}$ respectively. Thus,

- if $U_{1}\left(E D_{1}\right)-p_{1}<0$ and $U_{2}\left(E D_{2}\right)-p_{2}<0$, the user will opt out of both WSPs;

- if $U_{1}\left(E D_{1}\right)-p_{1}>U_{2}\left(E D_{2}\right)-p_{2}>0$, the user will subscribe to WSP ${ }_{1}$;

- if $U_{2}\left(E D_{2}\right)-p_{2}>U_{1}\left(E D_{1}\right)-p_{1}>0$, the user will subscribe to $\mathrm{WSP}_{2}$;

- only if $U_{1}\left(E D_{1}\right)-p_{1}=U_{2}\left(E D_{2}\right)-p_{2}>0$, the user is indifferent between $\mathrm{WSP}_{1}$ and $\mathrm{WSP}_{2}$.

In the situation in which the indifference relation

$$
U_{1}\left(E D_{1}\right)-p_{1}^{*}=U_{2}\left(E D_{2}\right)-p_{2}^{*}
$$

holds, a newly arriving user randomly selects $\mathrm{WSP}_{i}$ with probability $50 \%$, and there is no incentive for a user who has already joined one WSP to unilaterally change his current strategy because user derives no benefit from switching to another WSP. Therefore, the pair of prices $\left(p_{1}^{*}, p_{2}^{*}\right)$, which also maximize $\Pi_{1}$ and $\Pi_{2}$ simultaneously, is a Nash equilibrium. In equilibrium, the distribution of users between the two APs is stable beacuse the compensated utility $\mathbb{U}_{i}\left(E D_{i}\right)$ with both WSPs are the same. Indeed, if for a newly arriving user the compensated utility with the $\mathrm{WSP}_{1}, \mathbb{U}_{1}\left(E D_{1}\right)$, is greater than the compensated utility with the $\mathrm{WSP}_{2}, \mathbb{U}_{2}\left(E D_{2}\right)$, the newly arriving user would choose $\mathrm{WSP}_{1}$ and the existing users with $\mathrm{WSP}_{2}$ would switch to $\mathrm{WSP}_{1}$ until the compensated utility with $\mathrm{WSP}_{1}$ reaches that with $\mathrm{WSP}_{2}$. Addtionally, in equilibrium, both WSPs also have no unilateral incentive to change their current optimal prices, because changing price could lead to an increase or decrease in the user' compensated utility and create an incentive for the user to change his strategy.

\subsection{Duopoly queuing model}

We first assume that there are $N$ independent users in this duopoly. All the users generate information packets that they feed into the system after they submit to a WSP. The users who submit to the same WSP share a First-In-First-Serve (FIFS) based queuing and scheduling system. To simplify the analysis, we assume the information packets arrival process and the service time distributions, respectively, are Poisson and Exponential, which is called $\mathrm{M} / \mathrm{M} / 1$ model (Hock, 1996). In this M/M/1/FCFS system, packets generated by the $N$ users arrive 
according to a Poisson process with mean rate $\lambda N$ (this rate includes those who select to opt out of both WSPs) and the service times of individual packet for both WSPs are i.i.d. exponentially distributed with mean $\mu^{-1}$ given the assumption that both APs have the same bandwidth. Thus, the mean packet delay for $\mathrm{WSP}_{i}$ is:

$$
E D=\frac{1}{\mu-\lambda N E_{i}\left(p_{i}\right)}
$$

where $E\left(p_{i}\right)$ is the expectation of the acceptance for the price $p_{i}$. Note that Equation 7 only holds provided that $\mu>\lambda N E\left(p_{i}\right)$. We will show later that even though these system parameters are important for our analysis the equilibrium prices in our pricing model are independent of any system parameter. Since the user's compensated utility is a function of the response time, $E D$, the only information that a user needs to know is the response times of the packets generated by him when making his choice. We believe that it is practically possible for a WSP to inform each user of the response time of the packets generated by him. In (Jagannatha et al., 2002) Jagannathan et al. suggest a parameterized customer behavior model for customer's willingness-to-pay to a given price using a Pareto distribution of customer capacity to pay. Every customer has the capacity to pay based on a Pareto distribution with scale $b$ and shape $\alpha$, where all customers have capacities at least as large as $b$ and $\alpha$ determines how the capacities are distributed. The greater the value of $\alpha$, the fewer the users who can pay more than $b$. When $\alpha \rightarrow \infty$, all users have the same capacity $b$. However, for a normal service, the shape $\alpha$ would be expected to be a very large but finite number. It is reasonable to assume that users' willingness-to-pay is associated with their capacities to pay. Therefore, the expectation of acceptance for a given price $p_{i}$ is:

$$
E_{i}\left(p_{i}\right)= \begin{cases}1-\frac{\alpha_{i}}{\alpha_{i}+\delta_{i}}\left(\frac{p_{i}}{b_{i}}\right)^{\delta_{i}} & 0 \leq p_{i} \leq b_{i} \\ \frac{\delta_{i}}{\alpha_{i}+\delta_{i}}\left(\frac{b_{i}}{p_{i}}\right)^{\alpha_{i}} & p_{i}>b_{i}\end{cases}
$$

where shape $\alpha_{i}$, scale $b_{i}$ and user-willingness elasticity $\delta_{i}$ are determined by $\mathrm{WSP}_{i}$ based on its own observation. Different WSPs should have different values of these parameters. Since a WSP provider can observe the users' acceptance to the quoted price online, these parameters can be learned using an adaptive algorithm suggested by Jagannathan et al. in (Jagannatha et al., 2002) from the observed acceptance rate for a given price. In fact, the process of learning these parameters is a dynamic process with an aim to adjust the quoted price in line with the change of the user's compensated utility. The objective of dynamically learning these parameters is to capture the time-varying feature of customer behavior.

Then the expression for the user's compensated utility $U_{i}$ with $\mathrm{WSP}_{i}$ can be written as:

$$
\mathbb{U}_{i}=U_{i}\left(E D_{i}\right)-p_{i}=1 / E D_{i}-p_{i}=\mu-\lambda N E_{i}\left(p_{i}\right)-p_{i} .
$$

According to the analysis of Nash equilibrium in previous section, a pair of prices $\left(p_{1}^{*}, p_{2}^{*}\right)$ is in Nash equilibrium if and only if the following condition is satisfied:

$$
\begin{array}{cl} 
& E_{2}\left(p_{2}^{*}\right)-E_{1}\left(p_{1}^{*}\right)=\frac{p_{1}^{*}-p_{2}^{*}}{\lambda N}, \\
\text { subject to } & \mu-\lambda N E_{1}\left(p_{1}^{*}\right)-p_{1}^{*}>0 \text { or } \mu-\lambda N E_{2}\left(p_{2}^{*}\right)-p_{2}^{*}>0 .
\end{array}
$$

In the next section we will study the problem of identifying the Nash equilibrium prices $\left(p_{1}^{*}, p_{2}^{*}\right)$ between the two WSPs. 


\subsection{The price selection problem}

The profit of $\mathrm{WSP}_{i}$ is defined as the expected number of packets transmitted by the users who subscribe to $\mathrm{WSP}_{i}$ per unit time, multiplied by the difference between the price per packet, $p_{i}$, and the cost per packet, $c_{i}$. Thus the profit function for AP $i$ per unit time, $\Pi_{i}$, for a given price $p_{i}$ is given by:

$$
\Pi_{i}=\lambda N E_{i}\left(p_{i}\right)\left(p_{i}-c_{i}\right)
$$

Since an AP provider's prime concern is cost recovery, it is reasonable to assume that an WSP will set its price greater than or at least equal to its cost $c_{i}$,

The objective of each WSP is to select a price that will maximize its profit. Therefore, a strategic equilibrium $\left(p_{1}^{*}, p_{2}^{*}\right)$ for the two WSPs has to satisfies the following relations first:

$$
\begin{aligned}
& \forall p_{1}: \Pi_{1}\left(p_{1}^{*}\right) \geq \Pi_{1}\left(p_{1}\right) \\
& \forall p_{2}: \Pi_{1}\left(p_{2}^{*}\right) \geq \Pi_{2}\left(p_{2}\right)
\end{aligned}
$$

Mathematically, the profit of APi is maximized for the first order condition $\frac{\partial \Pi_{i}}{\partial p_{i}}=0$. There are two cases need to be discussed:

- CASE 1: When $p_{i}>b_{i}, E_{i}\left(p_{i}\right)=\frac{\delta_{i}}{\alpha_{i}+\delta_{i}}\left(\frac{b_{i}}{p_{i}}\right)^{\alpha_{i}}$, with which

$$
\Pi_{i}\left(p_{i}\right)=\lambda N \frac{\delta_{i}}{\alpha_{i}+\delta_{i}}\left(\frac{b_{i}}{p_{i}}\right)^{\alpha_{i}}\left(p_{i}-c_{i}\right) ;
$$

- CASE 2: When $0 \leq p_{i} \leq b_{i}, E_{i}\left(p_{i}\right)=1-\frac{\alpha_{i}}{\alpha_{i}+\delta_{i}}\left(\frac{p_{i}}{b_{i}}\right)^{\delta_{i}}$, with which

$$
\Pi_{i}\left(p_{i}\right)=\lambda N\left[1-\frac{\alpha_{i}}{\alpha_{i}+\delta_{i}}\left(\frac{p_{i}}{b_{i}}\right)^{\delta_{i}}\right]\left(p_{i}-c_{i}\right) .
$$

It can be proved that there is at least one maximization point in the range of $c_{i} \leq p_{i} \leq b_{i}$ and $p_{i}>b_{i}$ respectively. Thus, solving the following maximization problem gives the optimal price at which the $\mathrm{WSP}_{i}$ maximizes its profit:

$$
\max \Pi_{i}\left(p_{i}\right)= \begin{cases}\lambda N\left[1-\frac{\alpha_{i}}{\alpha_{i}+\delta_{i}}\left(\frac{p_{i}}{b_{i}}\right)^{\delta_{i}}\right]\left(p_{i}-c_{i}\right) & c_{i} \leq p_{i} \leq b_{i} \\ \lambda N \frac{\delta_{i}}{\alpha_{i}+\delta_{i}}\left(\frac{b_{i}}{p_{i}}\right)^{\alpha_{i}}\left(p_{i}-c_{i}\right) & p_{i}>b_{i} .\end{cases}
$$

Since a user has three options: subscribing to $\mathrm{WSP}_{1}$, subscribing to $\mathrm{WSP}_{2}$ or opting out of both of them, $\sum_{i=1}^{2} E_{i}\left(p_{i}\right)$ must be smaller than or equal to 1 . Note that here $E_{i}\left(p_{i}\right)$ is the acceptance rate at which $\mathrm{WSP}_{i}$ 's expected profit is maximized. In other words, only if $\mathrm{WSP}_{i}$ ensures the acceptance rate $E_{i}\left(p_{i}\right)$, can the best payoff be achieved by choosing the optimal price $p_{i_{o p t}}$. Combining the constraint condition $\sum_{i=1}^{2} E_{i}\left(p_{i}\right) \leq 1$ with Equation 10 and Equation 15 , the optimal price $p_{i_{\text {opt }}}$ that maximizes $\mathrm{WSP}_{i}^{\prime}$ 's excepted profits must satisfy:

$$
\begin{gathered}
\max _{i \in\{1,2\}} \Pi_{i}\left(p_{i}\right)= \begin{cases}\lambda N\left[1-\frac{\alpha_{i}}{\alpha_{i}+\delta_{i}}\left(\frac{p_{i}}{b_{i}}\right)^{\delta_{i}}\right]\left(p_{i}-c_{i}\right) & c_{i} \leq p_{i} \leq b_{i} \\
\lambda N \frac{\delta_{i}}{\alpha_{i}+\delta_{i}}\left(\frac{b_{i}}{p_{i}}\right)^{\alpha_{i}}\left(p_{i}-c_{i}\right) & p_{i}>b_{i},\end{cases} \\
\text { subject to } \mathbb{U}_{1}=\mathbb{U}_{2}>0 \text { and } E_{1}\left(p_{1}\right)+E_{2}\left(p_{2}\right) \leq 1 .
\end{gathered}
$$

However, Equation 16 is difficult to solve mathematically. To investigate the Nash equilibrium for this model, we provide numerical examples in the following section. 


\subsection{Numerical Examples}

Since there is at least one maximization point for $\Pi_{i}$ defined in Equation 16 within the ranges of $c_{i} \leq p_{i} \leq b_{i}$ and $p_{i}>b_{i}$ respectively, we have to study the expression for $\Pi_{i}$ further to determine which one is the maximization point for all $p_{i}>c_{i}$. Indeed, there is only one maximum for the profit function defined in Equation 15 within the ranges of $p_{i} \geq c_{i}$ as shown in Fig. 4(a). Fig. 4(b) further plots the expected profit per unit time for different assumed values of willingness elasticity parameter, $\delta_{i}$, with $\alpha_{i}=4, b_{i}=8$ and $c_{i}=5$. As can be observed, the willingness elasticity parameter, $\delta_{i}$, has no affect on the value of the optimal price, $p_{i_{o p t}}$. Without loss of generality and so as to simplify the analysis, we assume $\delta_{i}=2$ for both WSPs. Fig. 4(c) plots the expected profit per unit time for different assumed values of shape, $\alpha_{i}$, with $b_{i}=8, \delta_{i}=2$ and $\operatorname{cost}_{i}=5$. It can be seen that the value of the optimal price, $p_{i_{o p t}}$, is sightly affected by the value of shape, $\alpha_{i}$. For instance, when $\alpha_{i}=3$ the corresponding $p_{i_{\text {opt }}}$ is 7.9 while when $\alpha_{i}=13$ the corresponding $p_{i_{\text {opt }}}$ is 6.9. Note that the shape $\alpha$ is supposed to be a very large number for a normal service. For ease of illustration, we assume $\alpha_{i}=10$ and $\delta_{i}=2$. Then the maximization problem in Equation 16 becomes:

$$
\begin{gathered}
\max _{i \in\{1,2\}} \Pi_{i}\left(p_{i}\right)= \begin{cases}\lambda N\left[1-\frac{5}{6}\left(\frac{p_{i}}{b_{i}}\right)^{2}\right]\left(p_{i}-c_{i}\right) & c_{i} \leq p_{i} \leq b_{i} ; \\
\frac{1}{6} \lambda N\left(\frac{b_{i}}{p_{i}}\right)^{10}\left(p_{i}-c_{i}\right) & p_{i}>b_{i},\end{cases} \\
\text { subject to } \mathbb{U}_{1}\left(p_{1_{\text {opt }}}\right)=\mathbb{U}_{2}\left(p_{2_{\text {opt }}}\right)>0 \text { and } E_{1}\left(p_{1_{\text {opt }}}\right)+E_{2}\left(p_{2_{\text {opt }}}\right) \leq 1 .
\end{gathered}
$$

Thus, we obtain the optimal price as

$$
p_{i_{o p t}}= \begin{cases}\frac{1}{3}\left(c_{i}+\sqrt{c_{i}^{2}+\frac{18}{5} b_{i}^{2}}\right) & c_{i} \leq p_{i} \leq b_{i} \\ \frac{10}{9} c_{i} & p_{i}>b_{i} .\end{cases}
$$

Clearly, when $b_{i} \geq \frac{10}{9} c_{i}, p_{i}=\frac{1}{3}\left(c_{i}+\sqrt{c_{i}^{2}+\frac{18}{5} b_{i}^{2}}\right)$ is the maximum of the profit function defined in Equation 17, while when $b_{i}<\frac{10}{9} c_{i}, p_{i}=\frac{10}{9} c_{i}$ is the maximum. Since dynamic pricing is our main concern, in the rest of the chapter we will confine attention to the case of $b_{i} \geq \frac{10}{9} c_{i}$ and study the Nash equilibrium prices for this case.

Summarily, under the assumption $\alpha_{i}=10$ and $\delta_{i}=2$, a pair of strategic equilibrium prices $\left(p_{1}^{*}, p_{2}^{*}\right)$ for the two WSPs has to satisfies the following maximization problem:

$$
\begin{gathered}
\max _{i \in\{1,2\}} \Pi_{i}\left(p_{i}\right)=\lambda N\left[1-\frac{5}{6}\left(\frac{p_{i}}{b_{i}}\right)^{2}\right]\left(p_{i}-c_{i}\right) \\
\text { subject to } \mathbb{U}_{1}\left(p_{1_{\text {opt }}}\right)=\mathbb{U}_{2}\left(p_{2_{\text {opt }}}\right)>0 \text { and } E_{1}\left(p_{1_{\text {opt }}}\right)+E_{2}\left(p_{2_{\text {opt }}}\right) \leq 1,
\end{gathered}
$$

where $b_{i} \geq \frac{10}{9} c_{i}$ and $E_{i}\left(p_{i}\right)=1-\frac{\alpha_{i}}{\alpha_{i}+\delta_{i}}\left(\frac{p_{i}}{b_{i}}\right)^{\delta_{i}}$. Note that the corresponding optimal price $p_{i_{\text {opt }}}=$ $\frac{1}{3}\left[c_{i}+\sqrt{c_{i}^{2}+\frac{18}{5} b_{i}^{2}}\right]$.

In order to investigate the Nash equilibrium in this model, we performed the following simulations in which two WSPs provide wireless services in a market with $N=30$ users. Each user generates packets according to a Poisson process with rate $\lambda=10 \mathrm{packet} / \mathrm{sec}$, and the service times of individual packet are i.i.d. exponentially distributed with mean $300^{-1} \mathrm{sec}$. The costs of $\mathrm{WSP}_{1}$ and $\mathrm{WSP}_{2}$ per packet are $c_{1}=7$ and $c_{2}=5$ units respectively. Assume that both WSPs choose $\alpha=10$ and $\delta=2$. Then WSP $_{i}{ }^{\prime}$ s optimal price, $p_{i_{\text {opt }}}$, is $\frac{1}{3}\left[c_{i}+\sqrt{c_{i}^{2}+\frac{18}{5} b_{i}^{2}}\right]$. 


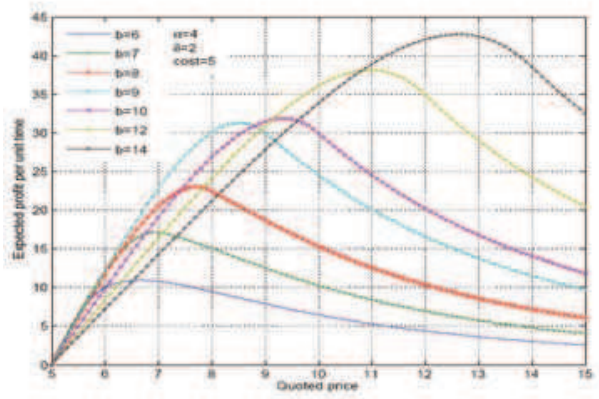

(a) Expected profit per unit time versus quoted price (varying scale parameter $b$ )

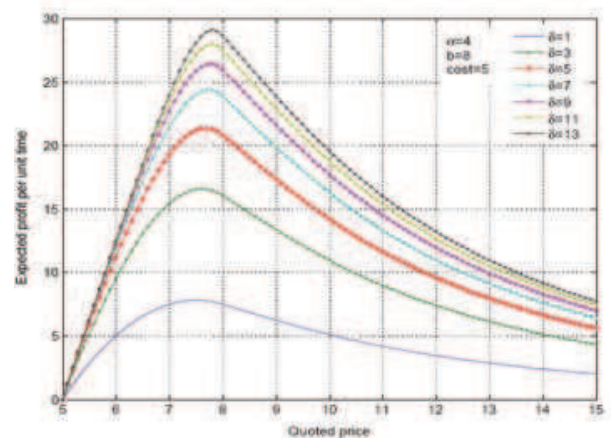

(b) Expected profit per unit time versus quoted price (varying willingness elasticity parameter $\delta$ )

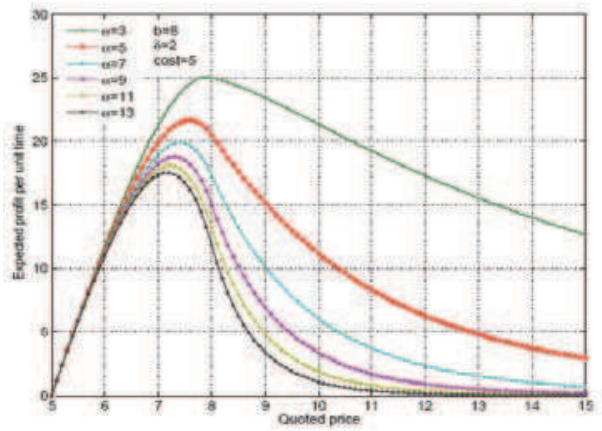

(c) Expected profit per unit time versus quoted price (varying willingness elasticity parameter $\alpha$ )

Fig. 4. Expected profit per unit time versus quoted price under different parameters 
For the sake of ease of simulation, $\mathrm{WSP}_{i}$ 's prices fall into the range of $\left[c_{i}, 2 c_{i}\right]$, which implies that $\frac{10}{9} c_{i} \leq b_{i} \leq \sqrt{\frac{20}{3}} c_{i}$ and $0.167 \leq E_{i}\left(p_{i_{\text {opt }}}\right) \leq 0.5$.

Since a Nash equilibrium would exist when Equation 10 holds, the following expression can be derived:

$$
p_{1_{\text {opt }}}^{*}-p_{2_{\text {opt }}}^{*}=\frac{5}{54} \lambda N\left[\left(\xi_{1}+{\sqrt{\xi_{1}^{2}+\frac{18}{5}}}^{2}-\left(\xi_{2}+{\sqrt{\xi_{2}^{2}+\frac{18}{5}}}^{2}\right],\right.\right.
$$

where $\xi_{1}=\frac{c_{1}}{b_{1}}$ and $\xi_{2}=\frac{c_{2}}{b_{2}}$. Combining the constraint condition $\sum_{i=1}^{2} E_{i}\left(p_{i}\right) \leq 1$, Nash equilibrium prices $\left(p_{1_{\text {opt }}}^{*}, p_{2_{\text {opt }}}^{*}\right)$ can be obtained. Evidently, Nash equilibrium prices $\left(p_{1_{\text {opt }}}^{*}, p_{2_{\text {opt }}}^{*}\right)$ are dependent on the ratio of the cost, $c_{i}$, and the parameter, $b_{i}$, of the probabilistic model for user's willingness-to-pay.

In the simulation, a two-dimensioned numerical search procedure is employed to obtain the equilibrium prices. The search procedure is described as follows. Firstly, $\mathrm{WSP}_{i}(i=$ 1,2) determines $b_{i}$ according to algorithm 1 and calculates corresponding $p_{i_{\text {opt }}}$, respectively. Note that here variable $b_{i}$ is used to represent the users' different responses to the WSPs' quoted prices. For convenience, in the rest of section, $p_{i_{o p t}}$ and $p_{i}$ are interchangeable. Let $\left\{p_{1}^{1}, p_{1}^{2}, \cdots, p_{1}^{n}\right\}$ and $\left\{p_{2}^{1}, p_{2}^{2}, \cdots, p_{2}^{n}\right\}$ be optimal price strategy forms of $\mathrm{WSP}_{1}$ and $\mathrm{WSP}_{2}$ respectively. We start by finding the expected user's compensated utilities with $\mathrm{WSP}_{1}$ and $\mathrm{WSP}_{2}$ respectively, given that $\mathrm{WSP}_{0}$ and $\mathrm{WSP}_{1}$ set their prices according to their optimal price strategy forms respectively. We first keep $\mathrm{WSP}_{1}$ 's price fixed at $p_{1}^{1}$, while $\mathrm{WSP}_{2}$ 's price continuously changes according to its price strategy form $\left\{p_{2}^{1}, p_{2}^{2}, \cdots, p_{2}^{n}\right\}$. The continuous price change allows us to identify the equilibrium compensated utilities, namely $\mathbb{U}_{0}=\mathbb{U}_{1}$. Thus, the equilibrium prices, $\left(p_{1}^{1 *}, p_{2}^{1 *}\right)$, that correspond to the equilibrium compensated utilities are identified. We then proceed to the next price in $\left\{p_{1}^{1}, p_{1}^{2}, \cdots, p_{1}^{n}\right\}$.

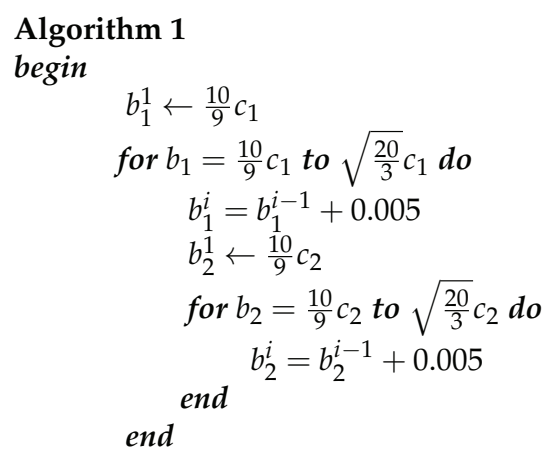

end

Fig. 5 illustrates the value difference between $\mathbb{U}_{2}\left(p_{2}\right)$ and $\mathbb{U}_{1}\left(p_{1}\right), \mathbb{U}_{2}\left(p_{2}\right)-\mathbb{U}_{1}\left(p_{1}\right)$, under different pairs of prices $\left(p_{1}, p_{2}\right)$. The pairs of prices that make $\mathbb{U}_{2}\left(p_{2}\right)=\mathbb{U}_{1}\left(p_{1}\right)$ are Nash equilibrium prices we are looking for. Note that using the $b_{i}$ obtained according to the above algorithm one could only find out pairs of prices $\left(p_{1}, p_{2}\right)$ which make $\mathbb{U}_{2}\left(p_{2}\right)-\mathbb{U}_{1}\left(p_{2}\right) \approx 0$. Here, we actually refer to the pairs of prices $\left(p_{1}, p_{2}\right)$ which make $\mathbb{U}_{2}\left(p_{2}\right)-\mathbb{U}_{1}\left(p_{1}\right) \approx 0$ as Nash equilibrium prices, which is represented as $\left(p_{1}^{*}, p_{2}^{*}\right)$

Table 1 lists some pairs Nash equilibrium prices and the corresponding acceptance rates. As is observed, both WSPs have to set their price within a certain range so that the constraint 


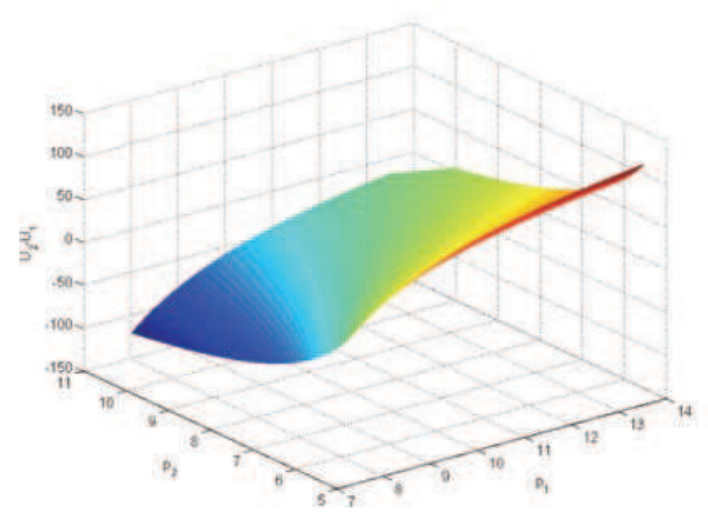

Fig. 5. $\mathbb{U}_{2}\left(p_{2}\right)-\mathbb{U}_{1}\left(p_{1}\right)$

\begin{tabular}{|l|l|l|l|l|l|l|}
\hline$p_{1}$ & 9.8033 & 10.77 & 11.71 & 12.78 & 13.28 & 13.688 \\
\hline$E_{1}\left(p_{1}\right)$ & 0.3638 & 0.4118 & 0.4458 & 0.4749 & 0.4861 & 0.4942 \\
\hline$p_{2}$ & 7.114 & 7.8227 & 8.6116 & 9.4802 & 9.9847 & 10.236 \\
\hline$\left.E_{2} p_{2}\right)$ & 0.3727 & 0.4192 & 0.4562 & 0.4859 & 0.4973 & 0.5057 \\
\hline
\end{tabular}

Table 1. Nash equilibrium price versus Nash equilibrium acceptance rate

$E_{1}\left(p_{1}^{*}\right)+E_{2}\left(p_{2}^{*}\right) \leq 1$ can be satisfied. For instance, as shown in Table 1 , when the $\mathrm{WSP}_{2}$ with lower price increases its price higher than twice its cost, $E_{2}\left(p_{2}^{*}\right)>0.5$, as a response, $\mathrm{WSP}_{1}$ with higher price also increases its price, which in turn lead to $E_{1}\left(p_{1}^{*}\right)+E_{2}\left(p_{2}^{*}\right)>1$. It implies that these two WSPs cannot increase their price as high as they want without cooperation.

Table 2 lists the user's compensated utilities with the two WSPs under different prices. As can be observed, for example, if $\mathrm{WSP}_{1}$ initially sets its price at 12.906 while $\mathrm{WSP}_{2}$ initially sets its price as 5.635, $\mathbb{U}_{1}\left(p_{1}\right)<\mathbb{U}_{2}\left(p_{2}\right)$ and the users will choose to subscribe or switch to $\mathrm{WSP}_{2}$. Then $\mathrm{WSP}_{1}$ will have to decrease its price to attract more users, while $\mathrm{WSP}_{2}$ would increase its price considering its congestion situation or just leave its price unchanged. This price adjusting process will be repeated until $p_{1}$ and $p_{2}$ converge to the point at which the compensated utility experienced by the users with $\mathrm{WSP}_{1}, \mathbb{U}_{1}$, is equal to the compensated utility experienced by the users with $\mathrm{WSP}_{2}, \mathbb{U}_{2}$. For instance, $\mathrm{WSP}_{1}$ decreases its price to 11.084 while $\mathrm{WSP}_{2}$ increases its price to 8.112. At this point, $\mathbb{U}_{1}\left(p_{1}^{*}\right)=\mathbb{U}_{2}\left(p_{2}^{*}\right)$, no WSP has any incentive to deviate from its price without the cooperation of the other, which may not happen, until existing users voluntarily disconnect or new users join in.

When the number of users in this market $N$ changes, $\mathbb{U}_{1}\left(p_{1}\right)$ and $\mathbb{U}_{2}\left(p_{2}\right)$ change accordingly, which in turn leads to the Nash equilibrium moving. This results in another round of price adjustment among the two WSPs and the users. As shown in Table 3, if we suppose in the first round the number of users $N=30$ and the two WSPs end up with a Nash equilibrium with prices $p_{1}=11.818$ and $p_{2}=8.6976$ respectively. When the number of users $N$ increases or decreases, even if $\mathrm{WSP}_{1}$ keeps its price $p_{1}=11.818, \mathrm{WSP}_{2}$ has to change its price such that both WSPs and the users can reach a new equilibrium. Additionally, when some users with one WSP disconnect or some new users join in one WSP, the WSP could adjust its price considering its resource utility or congestion situation. This also could lead to a new round of adjustment. 


\begin{tabular}{|l|l|l|l|l|l|l|l|l|l|}
\hline$p_{1}$ & 8.246 & 8.995 & 9.791 & 10.237 & 11.084 & 11.818 & 12.478 & 12.906 & 13.685 \\
\hline $\mathbb{U}_{1}$ & 222.13 & 198.83 & 181.27 & 173.54 & 161.64 & 153.44 & 147.26 & 143.73 & 138.06 \\
\hline$p_{2}$ & 5.635 & 6.602 & 7.552 & 7.774 & 8.112 & 8.474 & 9.187 & 9.452 & 10 \\
\hline $\mathbb{U}_{2}$ & 239.16 & 195.38 & 171.46 & 167.29 & 161.64 & 156.37 & 147.75 & 145.02 & 140 \\
\hline
\end{tabular}

Table 2. Users' compensated utilities

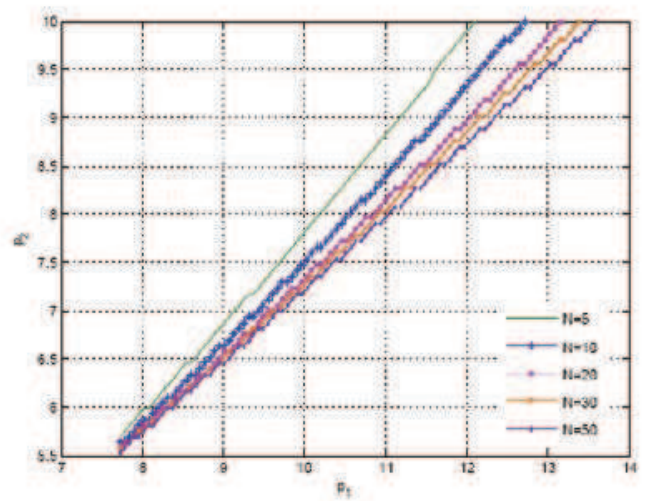

Fig. 6. Equilibrium prices for different number of users $N$

Fig. 6 plots the equilibrium points (at which $\mathbb{U}_{1}\left(p_{1}^{*}\right)-\mathbb{U}_{2}\left(p_{2}^{*}\right) \approx 0$ ) over $p_{1}$ and $p_{2}$ for various $N$. As can observed, for a given optimal price $p_{1}$ of $\mathrm{WSP}_{1}$, there is a unique optimal price $p_{2}$ of $\mathrm{WSP}_{2}$ so that $\mathrm{WSP}_{1}$ and $\mathrm{WSP}_{2}$ reach Nash equilibrium, and there is a quasi-linear relationship between $p_{1}^{*}$ and $p_{2}^{*}$. It is worth noting that this property is useful for a dynamic pricing competition. Since each optimal price $p_{i_{o p t}}$ corresponds to a certain value of $b_{i}$, which is determined by the traffic load of $\mathrm{WSP}_{i}$, if we simply assume, for $\mathrm{WSP}_{i}, b_{i}$ is varied with the number of users arriving at $\mathrm{WSP}_{i}$, sequentially, the optimal price $p_{i_{\text {opt }}}$ also varies in response to the change of the number of the arriving users. Suppose $\mathrm{WSP}_{1}$ and $\mathrm{WSP}_{2}$ set their optimal prices $p_{1}$ and $p_{2}$ based on the numbers of their arriving users respectively, but $p_{1}$ and $p_{2}$ are not in equilibrium. The users who receive a lower compensated utility will switch to another WSP, which in turn results in an increase of users at one WSP and a decrease of users at the alternative. Accordingly, $p_{1}$ and $p_{2}$ vary gradually until they converge to a Nash equilibrium point $\left(p_{1}^{*}, p_{2}^{*}\right)$.

\section{An extended pricing model for wireless oligopolies}

In this section, we extend the two-stage noncooperative game model described in Section 3 to a multi-provider setting as shown in Fig. 7.

\subsection{Model description}

Assume that there is a set $\mathbb{I}=\{0,1,2, \ldots, I-1\}$ of WSPs in a certain area to provide wireless services to $N$ potential users. Denote $p_{i}$ and $c_{i}$ as WSP ${ }_{i}{ }^{\prime}$ s price and cost per packet transmission respectively. Each user generates packets according to a Poisson process with mean rate $\lambda$. Then the potentially total mean arrival rate of packets in the whole network is given by $\lambda N$. Note that $\lambda N$ can be seen as an arrival rate when all potential users send out 


\begin{tabular}{|c|c|c|c|c|c|c|c|c|c|c|}
\hline \multirow{6}{*}{$N=5$} & $p_{1}$ & 8.246 & 8.9975 & 9.7912 & 10.237 & 11.084 & 11.818 & 12.112 & - & - \\
\hline & $\mathbb{U}_{1}$ & 280.15 & 275.64 & 272.05 & 270.39 & 267.7 & 265.73 & 265 & - & - \\
\hline & $\Pi_{1}$ & 14.46 & 30.64 & 50.68 & 62.71 & 86.63 & 108.19 & 117 & - & - \\
\hline & $p_{2}$ & 6.1613 & 6.8438 & 7.6099 & 8.0513 & 8.9159 & 9.6874 & 10 & - & - \\
\hline & $\mathbb{U}_{2}$ & 280.15 & 275.65 & 272.05 & 270.39 & 267.7 & 265.72 & 265 & - & - \\
\hline & $\Pi_{2}$ & 15.90 & 32.28 & 53.09 & 65.78 & 91.56 & 115.26 & 125 & - & - \\
\hline \multirow{6}{*}{$N=10$} & $p_{1}$ & 8.246 & 8.9945 & 9.7912 & 10.237 & 11.084 & 11.818 & 12.478 & 12.7 & - \\
\hline & $\mathbb{U}_{1}$ & 268.55 & 260.28 & 253.9 & 251.02 & 246.49 & 243.27 & 240.77 & 240 & - \\
\hline & $\Pi_{1}$ & 28.92 & 61.28 & 101.36 & 125.41 & 173.27 & 216.37 & 256.11 & 269.61 & - \\
\hline & $p_{2}$ & 6.0265 & 6.6407 & 7.3191 & 7.7071 & 8.4705 & 9.1531 & 9.7964 & 10 & - \\
\hline & $\mathbb{U}_{2}$ & 268.56 & 260.29 & 253.89 & 251.03 & 246.49 & 243.27 & 240.77 & 240 & - \\
\hline & $\Pi_{2}$ & 26.09 & 54.26 & 89.96 & 111.7 & 156.3 & 197.58 & 236.68 & 250 & - \\
\hline \multirow{6}{*}{$N=20$} & $p_{1}$ & 8.246 & 8.9945 & 9.7912 & 10.237 & 11.084 & 11.821 & 12.481 & 12.906 & 13.187 \\
\hline & $\mathbb{U}_{1}$ & 245.34 & 229.56 & 217.59 & 212.28 & 204.06 & 198.33 & 194 & 191.52 & 189.99 \\
\hline & $\Pi_{1}$ & 57.83 & 122.56 & 202.71 & 250.82 & 346.54 & 433.11 & 512.59 & 584.49 & 599.03 \\
\hline & $p_{2}$ & 5.9594 & 6.5336 & 7.1592 & 7.5159 & 8.2071 & 8.8205 & 9.3845 & 9.7544 & 10 \\
\hline & $\mathbb{U}_{2}$ & 245.33 & 229.57 & 217.59 & 212.28 & 204.05 & 198.34 & 194.01 & 191.5 & 190 \\
\hline & $\Pi_{2}$ & 47.74 & 97.99 & 162.48 & 201.78 & 281.39 & 354.68 & 423.58 & 469.5 & 500 \\
\hline \multirow{6}{*}{$N=30$} & $p_{1}$ & 8.246 & 8.9945 & 9.7912 & 10.237 & 11.084 & 11.818* & 12.478 & 12.906 & 13.685 \\
\hline & $\mathbb{U}_{1}$ & 222.13 & 198.83 & 181.24 & 173.54 & 161.64 & 153.44 & 147.26 & 143.73 & 138.06 \\
\hline & $\Pi_{1}$ & 86.75 & 183.84 & 304.07 & 376.23 & 519.8 & 649.12 & 768.32 & 846.73 & 991.04 \\
\hline & $p_{2}$ & 5.9361 & 6.498 & 7.105 & 7.4492 & 8.1124 & $8.6976^{*}$ & 9.2333 & 9.5853 & 10.236 \\
\hline & $\mathbb{U}_{2}$ & 222.13 & 198.83 & 181.27 & 173.54 & 161.64 & 153.44 & 147.26 & 143.73 & 138.06 \\
\hline & $\Pi_{2}$ & 67.34 & 141.81 & 234.96 & 291.49 & 405.39 & 509.75 & 607.48 & 672.59 & 794.28 \\
\hline \multirow{6}{*}{$N=35$} & $p_{1}$ & 8.246 & 8.9975 & 9.7912 & 10.237 & 11.084 & 11.821 & 12.478 & 12.906 & 13.474 \\
\hline & $\mathbb{U}_{1}$ & 210.53 & 183.38 & 163.12 & 154.17 & 140.42 & 130.95 & 123.89 & 119.84 & 115 \\
\hline & $\Pi_{1}$ & 101.21 & 214.97 & 354.74 & 438.94 & 606.44 & 757.95 & 896.38 & 987.85 & 1110.5 \\
\hline & $p_{2}$ & 5.9303 & 6.4891 & 7.09 & 7.431 & 8.8049 & 8.6638 & 9.1901 & 9.5358 & 10 \\
\hline & $\mathbb{U}_{2}$ & 210.48 & 183.41 & 161.1 & 154.14 & 140.43 & 130.96 & 123.88 & 119.83 & 115 \\
\hline & $\Pi_{2}$ & 77.76 & 163.91 & 271.3 & 336.53 & 467.33 & 587.59 & 699.46 & 773.97 & 875 \\
\hline \multirow{6}{*}{$N=40$} & $p_{1}$ & 8.246 & 8.9975 & 9.7912 & 10.237 & 11.084 & $11.818^{*}$ & 12.478 & 12.909 & 13.53 \\
\hline & $\mathbb{U}_{1}$ & 198.92 & 168.11 & 144.96 & 134.8 & 119.21 & 108.53 & 100.51 & 95.91 & 90 \\
\hline & $\Pi_{1}$ & 115.67 & 245.12 & 405.42 & 501.64 & 693.07 & 865.5 & 1024.4 & 1129.7 & 1282.9 \\
\hline & $p_{2}$ & 5.9245 & 6.4801 & 7.0779 & 7.4159 & 8.0635 & $8.6362^{*}$ & 9.1562 & 9.4988 & 10 \\
\hline & $\mathbb{U}_{2}$ & 198.93 & 168.09 & 144.95 & 134.78 & 119.23 & 108.51 & 100.51 & 95.92 & 90 \\
\hline & $\Pi_{2}$ & 87.96 & 185.66 & 307.48 & 381.24 & 529.1 & 664.89 & 791.08 & 875.37 & 1000 \\
\hline \multirow{6}{*}{$N=50$} & $p_{1}$ & 8.246 & 8.9945 & 9.7912 & 10.237 & 11.084 & $11.818^{*}$ & 12.481 & 12.906 & 13.614 \\
\hline & $\mathbb{U}_{1}$ & 175.72 & 137.39 & 108.65 & 96.06 & 76.78 & 63.62 & 53.72 & 48.16 & 39.99 \\
\hline & $\Pi_{1}$ & 144.58 & 306.4 & 506.78 & 627.06 & 806.34 & 1081.9 & 1281.5 & 1411.2 & 1629.6 \\
\hline & $p_{2}$ & 5.9187 & 6.4683 & 7.0599 & 7.3947 & 8.0361 & $8.5962^{*}$ & 9.1099 & 9.4432 & 10 \\
\hline & $\mathbb{U}_{2}$ & 175.64 & 137.41 & 108.69 & 96.06 & 76.77 & 63.63 & 53.73 & 48.15 & 40 \\
\hline & $\Pi_{2}$ & 209.95 & 288.67 & 517.49 & 629.44 & 707.32 & 842.3 & 935.83 & 1087.6 & 1181.6 \\
\hline
\end{tabular}

Table 3. Users' compensated utilities for different number of users $N$ 


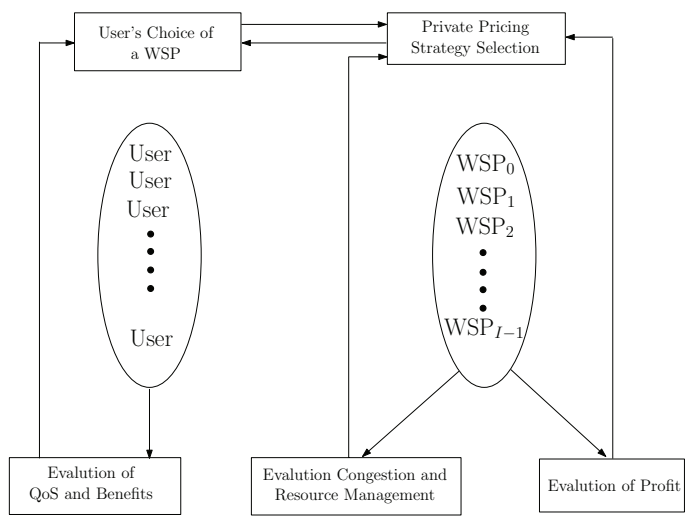

Fig. 7. Pricing model for multiple WSPs

all their requests without considering price or QoS. In addition, we stick to the mathematical definition of user's utility and compensated utility in Section 3. Then the user's compensated utility $\mathbb{U}_{i}$ with $\mathrm{WSP}_{i}$ can be expressed as:

$$
\mathbb{U}_{i}=U_{i}\left(E D_{i}\right)-p_{i}=1 / E D_{i}-p_{i}=\mu-\lambda N E_{i}\left(p_{i}\right)-p_{i},
$$

where $i=0,1,2, \ldots, I-1$.

Similar to the duopoly case, from a user's perspective,

- if $\mathbb{U}_{i}<0$ for all $i \in \mathbb{I}$, the user will opt out of all the WSPs;

- if $\mathbb{U}_{i}>0$ and $\mathbb{U}_{i}>\mathbb{U}_{-i}$, where the subscript $-i$ represents all the WSPs belonging to II except $i$ itself, the user will subscribe to $\mathrm{WSP}_{i}$;

- only if $\mathbb{U}_{0}=\cdots=\mathbb{U}_{i}=\cdots=\mathbb{U}_{I-1}>0$, the user is indifferent among these WSPs.

In the situation in which the indifference relation

$$
U_{0}\left(E D_{0}\right)-p_{0}^{*}=\cdots=U_{0}\left(E D_{0}\right)-p_{i}^{*}=\cdots=U_{I-1}\left(E D_{I-1}\right)-p_{I-1}^{*}>0
$$

holds, all the WSPs and users reach a Nash equilibrium and the set of prices $\left\{p_{0}^{*}, p_{1}^{*}, p_{2}^{*}, \cdots, p_{I-1}^{*}\right\}$ is the Nash equilibrium prices.

Similarly, the profit function for $\mathrm{WSP}_{i}$ per unit time, $\Pi_{i}$, is given by $\Pi_{i}=\lambda N E_{i}\left(p_{i}\right)\left(p_{i}-c_{i}\right)$. Thus, solving the following maximization problem gives $\mathrm{WSP}_{i}$ 's optimal price at which $\mathrm{WSP}_{i}$ maximizes its profit:

$$
\max \Pi_{i}\left(p_{i}\right)= \begin{cases}\lambda N\left[1-\frac{\alpha_{i}}{\alpha_{i}+\delta_{i}}\left(\frac{p_{i}}{b_{i}}\right)^{\delta_{i}}\right]\left(p_{i}-c_{i}\right) & c_{i} \leq p_{i} \leq b_{i} \\ \lambda N \frac{\delta_{i}}{\alpha_{i}+\delta_{i}}\left(\frac{b_{i}}{p_{i}}\right)^{\alpha_{i}}\left(p_{i}-c_{i}\right) & p_{i}>b_{i},\end{cases}
$$

where $i=0,1, \ldots, I-1$.

According to the previous analysis in Section 3, the maximization problem Equation 23 can be reduced to the following maximization problem:

$$
\begin{aligned}
& \underset{i \in 0,1, \ldots, I-1}{\max } \prod_{i}\left(p_{i}\right)=\lambda N\left[1-\frac{5}{6}\left(\frac{p_{i}}{b_{i}}\right)^{2}\right]\left(p_{i}-c_{i}\right) c_{i} \leq p_{i} \leq b_{i} \\
& \text { subject to } \mathbb{U}_{0}\left(p_{0_{\text {opt }}}\right)=\mathbb{U}_{1}\left(p_{1_{\text {opt }}}\right)=\ldots=\mathbb{U}_{I-1}\left(p_{I-1_{\text {opt }}}\right)>0 \\
& \text { and } \sum_{i=0}^{I-1} E_{i}\left(p_{i_{\text {opt }}}\right) \leq 1,
\end{aligned}
$$


where $b_{i} \geq \frac{10}{9} c_{i}$ and $E_{i}\left(p_{i}\right)=1-\frac{\alpha_{i}}{\alpha_{i}+\delta_{i}}\left(\frac{p_{i}}{b_{i}}\right)^{\delta_{i}}$. Note that the corresponding optimal price $p_{i_{o p t}}=$ $\frac{1}{3}\left[c_{i}+\sqrt{c_{i}^{2}+\frac{18}{5} b_{i}^{2}}\right]$.

In the next section, we will show the existence and uniqueness of Nash equilibrium in this oligopoly model.

\subsection{Equilibrium: existence and uniqueness}

In equilibrium, the distribution of users among the WSPs has to be stable from a macro perspective, meaning that a new arrival user will randomly subscribe to a particular $\mathrm{WSP}_{i}$ $(i=0,1,2, \cdots, I-1)$ and the users who already subscribed to a WSP have no incentive to switch to a different WSP. This indicates that the compensated utilities $\mathbb{U}_{i}(i=0,1,2, \cdots, I-1)$ should be non-negative and equal to each other for all $\mathrm{WSP}_{i}(i=0,1,2, \cdots, I-1)$. Without loss of generality, we assume that $c_{0}<c_{1}<c_{2}<\cdots<c_{I-1}$. We then take $\mathrm{WSP}_{0}$ 's optimal price $p_{0_{\text {opt }}}$ and cost $c_{0}$ as references such that the equilibrium price of $\operatorname{WSP}_{i}(i=1,2, \cdots, I-1)$ can be expressed as a function of $p_{0 \text { opt }}$ and $c_{0}$. The condition that all the compensated utilities $\mathbb{U}_{i}$ $(i=0,1,2, \cdots, I-1)$ are equal in equilibrium can be expressed as:

$$
\begin{array}{cl} 
& \mu-\lambda N E\left(p_{0_{o p t}}\right)-p_{0_{o p t}}=\mu-\lambda N E\left(p_{i_{o p t}}\right)-p_{i_{o p t}}, \\
\text { where } \quad & E_{i}\left(p_{i}\right)=1-\frac{5}{6}\left(\frac{p_{i}}{b_{i}}\right)^{2} ; \quad(25-2) \\
\text { and } \quad p_{i_{o p t}}=\frac{1}{3}\left(c_{i}+\sqrt{c_{i}^{2}+\frac{18}{5} b_{i}^{2}}\right), \quad \text { (25-3) }
\end{array}
$$

for all $i=0,1,2, \cdots, I-1$.

From Equation 25-3, we obtain:

$$
6 b_{i}^{2}=15 p_{i_{o p t}}^{2}-10 p_{i_{o p t}} c_{i} .
$$

Substituting $b_{i}$ into Equation 25-2, we get:

$$
E_{i}\left(p_{i_{o p t}}\right)=1-\frac{p_{i_{o p t}}}{3 p_{i_{o p t}}-2 c_{i}} .
$$

Substituting $E_{i}\left(p_{i_{o p t}}\right)$ into Equation 25-1 results in:

$$
p_{i_{o p t}}-p_{0_{o p t}}=\lambda N\left(\frac{p_{i_{o p t}}}{3 p_{i_{o p t}}-2 c_{i}}-\frac{p_{0_{o p t}}}{3 p_{0_{o p t}}-2 c_{0}}\right) .
$$

Dividing $p_{0_{o p t}}$ on both sides of Equation 28 and denoting $\frac{p_{i_{\text {opt }}}}{p_{0_{o p t}}}$ by $\xi_{i}$, we have

$$
\xi_{i}-1=\lambda N\left(\frac{\xi_{i}}{3 p_{i_{o p t}}-2 c_{i}}-\frac{1}{3 p_{0_{o p t}}-2 c_{0}}\right)
$$

Substituting $\frac{6 b_{i}^{2}}{5 p_{i_{o p t}}}$ for $3 p_{i_{o p t}}-2 c_{i}$, Equation 29 can be rewritten as:

$$
\xi_{i}\left(\frac{5 p_{i_{o p t}} \lambda N}{6 b_{i}^{2}}-1\right)=\frac{5 p_{0_{o p t}} \lambda N}{6 b_{0}^{2}}-1 .
$$


Dividing $p_{0_{o p t}}$ on both sides of Equation 30 again, we can obtian

$$
\xi_{i}\left(\frac{5 \xi_{i} \lambda N}{6 b_{i}^{2}}-\frac{1}{p_{0_{o p t}}}\right)=\frac{5 \lambda N}{6 b_{0}^{2}}-\frac{1}{p_{0_{o p t}}} .
$$

Here Equation 31 is a quadratic equation in $\xi_{i}$, which can be rewritten as:

$$
a_{1} \xi_{i}^{2}+a_{2} \xi_{i}+a_{3}=0
$$

where

$$
a_{1}=\frac{5 \lambda N}{6 b_{i}^{2}}, \quad a_{2}=-\frac{1}{p_{0_{o p t}}}, \quad a_{3}=\frac{1}{p_{0_{o p t}}}-\frac{5 \lambda N}{6 b_{0}^{2}} .
$$

The solutions to Equation 32 are $\frac{-a_{2} \pm \sqrt{a_{2}^{2}-4 a_{1} a_{3}}}{2 a_{1}}$, in which

$$
a_{2}^{2}-4 a_{1} a_{3}=\frac{1}{p_{0_{o p t}}^{2}}+\frac{25 \lambda^{2} N^{2}}{9 b_{0}^{2} b_{i}^{2}}-\frac{10 \lambda N}{3 p_{0_{o p t}} b_{i}^{2}}
$$

It is straightforward to prove that $\frac{25 \lambda^{2} N^{2}}{9 b_{0}^{2} b_{i}^{2}}>\frac{10 \lambda N}{3 p_{0 \text { opt }} b_{i}^{2}}$ given that $5 p_{0_{o p t}} \lambda N>6 b_{0}^{2}$, which can be rewritten as $\lambda N>3 p_{0_{o p t}}-2 c_{0}$. Later we will show that $p_{0_{o p t}} \leq 2 c_{0}$. Thus $\lambda N>3 p_{0_{o p t}}-2 c_{0} \geq$ $4 c_{0}$. Note that $\lambda N$ represents the mean rate that all $N$ users generate packets per second while $c_{0}$ is $\mathrm{WSP}_{0}$ 's per packet transmission. Therefore $c_{0}$ cannot be directly compared to $\lambda \mathrm{N}$. However, it is reasonable to assume that the cost per packet can be converted into a small enough unit such that $c_{0}<<\lambda N$, which means $5 p_{0_{o p t}} \lambda N>>6 b_{0}^{2}$ always holds.

Since $\frac{25 \lambda^{2} N^{2}}{9 b_{0}^{2} b_{i}^{2}}>\frac{10 \lambda N}{3 p_{0 \text { opt }} b_{i}^{2}}$, it can be proved that $a_{2}^{2}-4 a_{1} a_{3}>\frac{1}{p_{0_{o p t}}^{2}}>0$ and $\sqrt{a_{2}^{2}-4 a_{1} a_{3}}>-a_{2}$, meaning that the solutions to Equation 32 are real numbers and only one of them is positive. Note that $p_{i_{o p t}}$ for all $i=0,1,2, \cdots, I-1$ are positive. Therefore Equation 32 has a unique solution, which is a positive real number $\left(\frac{-a_{2}+\sqrt{a_{2}^{2}-4 a_{1} a_{3}}}{2 a_{1}}\right)$. Now it can be concluded that for all $i=1,2, \cdots, I-1, p_{i_{\text {opt }}}$ is linear with $p_{0_{\text {opt }}}$ with a coefficient $\xi_{i}=\frac{-a_{2}+\sqrt{a_{2}^{2}-4 a_{1} a_{3}}}{2 a_{1}}$. In other words, under the constraint $\sum_{i=0}^{I-1} E_{i}\left(p_{i_{o p t}}\right) \leq 1$, for an arbitrary $p_{0_{o p t}}$, there exists a unique $p_{i_{\text {opt }}}$ $(i=1,2, \cdots, I-1)$ in equilibrium with it.

Furthermore, by investigating the unique solution to Equation 32 , we find that $\xi_{i} \approx$ $\frac{\frac{1}{p_{0 p t}}+\sqrt{\frac{25 \lambda^{2} N^{2}}{9 b_{0}^{2} b_{i}^{2}}}}{\frac{5 \lambda N}{3 b_{i}^{2}}}>\frac{b_{i}}{b_{0}}$. Let $\frac{b_{i}}{b_{0}}$ be $k_{i}$. Thus $\xi_{i}=\gamma_{i} k_{i}$, where $\gamma_{i} \cong \frac{\frac{1}{p_{o p t}}}{\frac{5 \lambda N}{3 b_{i}^{2}}}+1$. It can be proved that $\gamma_{i}$ approximates to 1 but is strictly greater than 1. According to Equation 26,

$$
k_{i}^{2}=\frac{b_{i}^{2}}{b_{0}^{2}}=\frac{3 p_{i_{o p t}}^{2}-2 p_{i_{o p t}} c_{i}}{3 p_{0_{o p t}}^{2}-2 p_{0_{o p t}} c_{i}}=\frac{3 \gamma_{i}^{2} k_{i}^{2} p_{0_{o p t}}^{2}-2 \gamma_{i} k_{i} p_{0_{o p t}} c_{i}}{3 p_{0_{o p t}}^{2}-2 p_{0_{o p t}} c_{i}} .
$$

Solving Equation $33, k_{i}$ is given by

$$
k_{i}=\frac{2 \gamma_{i} c_{i}}{3 \gamma_{i}^{2} p_{0_{o p t}}-3 p_{0_{o p t}}+2 c_{0}} .
$$

Since $\gamma_{i} \cong 1, k_{i} \cong \gamma_{i} \frac{c_{i}}{c_{0}}$. 
In summary, $\frac{p_{i_{\text {opt }}}}{p_{0_{\text {opt }}}} \cong \gamma_{i} \frac{b_{i}}{b_{0}} \cong \gamma_{i}^{2} \frac{c_{i}}{c_{0}}$, where $\gamma_{i} \cong 1$, and under the constraint $\sum_{i=0}^{I-1} E_{i}\left(p_{i_{\text {opt }}}\right) \leq 1$, for an arbitrary $p_{0_{\text {opt }}}$, the higher the cost $c_{i}$ the greater $\gamma_{i}$, meaning for $\mathrm{WSP}_{i}$ the higher the cost $c_{i}$ the higher the corresponding equilibrium price, $p_{i_{\text {opt }}}$.

The constraint $\sum_{i=0}^{I-1} E_{i}\left(p_{i_{\text {opt }}}\right) \leq 1$ can be expressed as:

$$
\begin{aligned}
& I-\frac{5}{6}\left(\frac{p_{0_{o p t}}^{2}}{b_{0}^{2}}+\frac{p_{1_{o p t}}^{2}}{b_{1}^{2}}+\cdots+\frac{p_{I-1_{o p t}}^{2}}{b_{I-1}^{2}}\right) \\
= & I-\frac{5}{6} \frac{p_{0_{o p t}}^{2}}{b_{0}^{2}}\left(1+\gamma_{1}^{2}+\cdots+\cdots+\gamma_{I-1}^{2}\right) \\
\approx & I-I \frac{5}{6} \frac{p_{0_{o p t}}^{2}}{b_{0}^{2}} \\
= & I E_{0}\left(p_{0_{o p t}}\right) \leq 1 .
\end{aligned}
$$

Here Equation 35 indicates that the maximum value of $E_{0}\left(p_{0_{\text {opt }}}\right)$, which is denoted by $E_{0_{\max }}$, approximates to $\frac{1}{I}$. The corresponding optimal price is denoted as the maximum optimal price $p_{0_{\max }}$. Then, it is straightforward to prove that the greater the number of providers $I$ the lower the maximum optimal price $p_{0_{\max }}$ that $\mathrm{WSP}_{0}$ could reach. This in turn means that, in equilibrium, all other WSPs' maximum optimal prices, $p_{i_{\max }}$ for all $i=1,2, \cdots, I-1$, are lower accordingly. Thus, when more WSPs enter into the market, in equilibrium, the maximum prices they can charge decreases.

\subsection{Numerical examples}

In order to verify the analytical results obtained in the previous section, we performed the following simulations where several WSPs provide wireless services in a market with $N=40$ users. Each user generates packets according to a Poisson process with rate $\lambda=10 \mathrm{packet} / \mathrm{sec}$, and the service time of individual packet are i.i.d. exponentially distributed with mean $300^{-1}$ sec.

To study the impact of an entry of a new WSP on the existing WSPs, we first conducted a simulation where there are two WSPs: $\mathrm{WSP}_{0}$ and $\mathrm{WSP}_{1}$ competing in the market. The costs of $\mathrm{WSP}_{0}$ and $\mathrm{WSP}_{1}$ per packet are $c_{0}=5$ and $c_{1}=7$ units respectively. For convenience, in the rest of section, $p_{i_{\text {opt }}}$ and $p_{i}$ are interchangeable. Let $\left\{p_{0}^{1}, p_{0}^{2}, \cdots, p_{0}^{n}\right\}$ and $\left\{p_{1}^{1}, p_{1}^{2}, \cdots, p_{1}^{n}\right\}$ be optimal price strategy forms of $\mathrm{WSP}_{0}$ and $\mathrm{WSP}_{1}$ respectively. Using the same approach that we used to identify the equilibrium in Section 3, we find the set of the equilibrium prices $\left\{\left(p_{0}^{1 *}, p_{1}^{1 *}\right),\left(p_{0}^{2 *}, p_{1}^{2 *}\right), \ldots,\left(p_{0}^{n *}, p_{1}^{n *}\right)\right\}$, which is represented as $\left(p_{0}^{*}, p_{1}^{*}\right)$ in the rest of the section. Fig. $8\left(\right.$ a) plots $\left(p_{0}^{*}, p_{1}^{*}\right)$. As can be seen, in equilibrium, for an arbitrary $p_{0}^{*}$, there is a unique $p_{1}^{*}$ corresponding to it. In particular, $p_{0}^{*}$ is quasi-linear with $p_{1}^{*}$. Under the same assumptions, $p_{0_{\max }^{*}}^{*}$ and $p_{1_{\max }^{*}}^{*}$ are 9.997 and 13.526 respectively.

We then simulated another scenario where the third WSP, $\mathrm{WSP}_{2}$, joins $\mathrm{WSP}_{0}$ and $\mathrm{WSP}_{1}$. $\mathrm{WSP}_{2}$ 's cost per packet $c_{2}=9$ units and its optimal price strategy form is $\left\{p_{2}^{1}, p_{2}^{2}, \cdots, p_{2}^{n}\right\}$. Using the same approach, we obtained the equilibrium prices $\left(p_{0}^{\prime *}, p_{1}^{\prime *}, p_{2}^{\prime *}\right)$, which are plotted in Fig. 8(b) to compare with those obtained from the two-WSP scenario. As can be observed, in equilibrium, for an arbitrary $p_{0}^{\prime *}$, there are unique $p_{1}^{\prime *}$ and $p_{2}^{\prime *}$ corresponding to it respectively. Again, $p_{0}^{\prime *}$ is linear with $p_{1}^{\prime *}$ and $p_{2}^{\prime *}$ respectively. In addition, the range of values for the equilibrium prices $\left(p_{0}^{*}, p_{1}^{*}\right)$ in two-WSP case shown in Fig. $8(\mathrm{a})$ is larger than that in three-WSP 

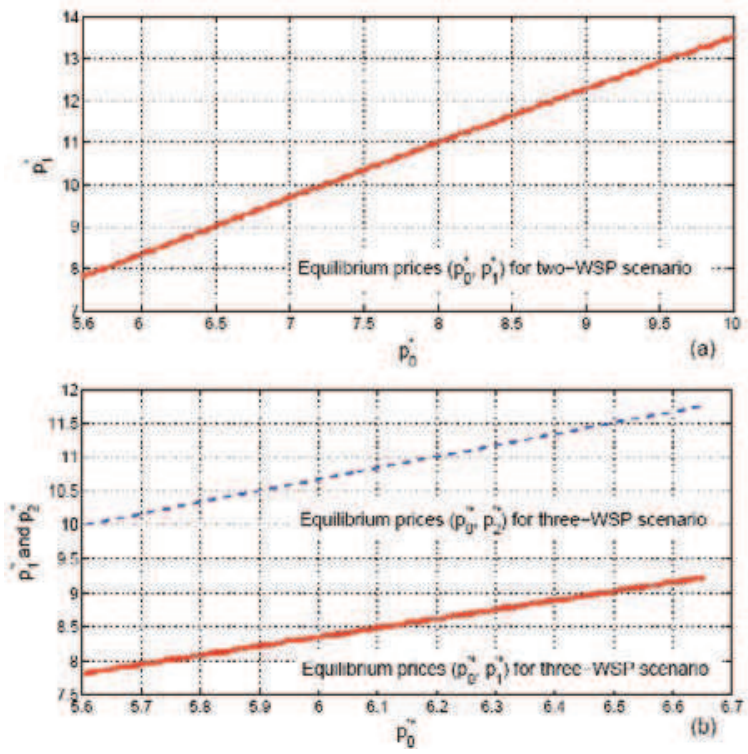

Fig. 8. Equilibrium prices: two-WSP scenario vs three-WSP scenario

case shown in Fig. 8(b). This is because of the equilibrium condition $\sum_{i=0}^{I-1} E_{i}\left(p_{i_{\text {opt }}}\right) \leq 1$ $\forall i=0,1,2, \cdots, I-1$, which restricts the allowed values for $p_{i}^{*}$ as analyzed in Equation 35 . When the number of WSPs increases to 3 from 2, under the same assumptions, the maximum equilibrium prices $p_{0_{\max }^{\prime}}^{*}$ and $p_{1_{\max }^{\prime}}^{*}$ are 6.623 and 9.186 respectively. Evidently, $p_{0_{\max }^{\prime}}^{*}$ and $p_{1_{\max }^{\prime}}^{*}$ are significantly lower than those obtained in two-WSP scenario.

Fig. 9 illustrates the expected profits of all WSPs associated with the equilibrium prices plotted in Fig. 8. Similarly, the range of the values for the expected profit in two-WSP case is larger than that of three-WSP case. As we can see, in three-WSP scenario, the expected profits of $\mathrm{WSP}_{0}$ and $\mathrm{WSP}_{1}$ are lower than those of two-WSP scenario, because $\mathrm{WSP}_{2}$ takes some market share.

When the number of potential users, $N$, in this market changes, the expected compensated utility $\mathbb{U}_{i}$ changes, which in turn changes the current Nash equilibrium. This leads to another round of price adjustment among the WSPs and the users. Table 3 lists some equilibrium prices, the corresponding expected compensated utilities and the corresponding expected acceptance rate with various number of potential users, $N$. As shown in Table 3, if we suppose in the first round $N=30$ and the three WSPs end up with a Nash equilibrium with $p_{0}=6.2970$, $p_{1}=8.7274$ and $p_{2}=11.114$. When the number $N$ changes, even if $\mathrm{WSP}_{0}$ keeps its price $p_{0}=6.2970$ unchanged, $\mathrm{WSP}_{1}$ and $\mathrm{WSP}_{2}$ have to change their price such that the three WSPs and the users can reach a new equilibrium.

It has been shown that, with the proposed pricing scheme, when a new WSP enters into a market with two or more WSPs already existing, the maximum equilibrium prices that the existing WSPs can reach will decrease. For a WSP, besides its traffic load status, cost is another factor determining its optimal prices, which in turn affects the WSPs' equilibrium prices. Thus, a follow-up question would be how the cost of the new WSP affects the equilibrium prices of the existing WSPs. Then another three-WSP scenario simulation, in which costs 


\begin{tabular}{|c|c|c|c|c|c|c|c|c|c|c|}
\hline \multirow{9}{*}{$N=10$} & $p_{0}$ & 5.7624 & 5.7769 & 5.9918 & 6.1528 & $6.2970^{*}$ & 6.3827 & 6.4864 & 6.5726 & 6.9011 \\
\hline & $\mathbb{U}_{0}$ & 273.31 & 273.03 & 269.09 & 266.59 & 264.53 & 263.39 & 262.09 & 261.06 & 257.58 \\
\hline & $E_{0}$ & 0.2092 & 0.2120 & 0.2487 & 0.2726 & 0.2918 & 0.3023 & 0.3143 & 0.3236 & 0.3552 \\
\hline & $p_{1}$ & 7.9153 & 7.9325 & 8.2041 & 8.4020 & $8.5776^{*}$ & 8.6833 & 8.807 & 8.9133 & 9.3052 \\
\hline & $\mathbb{U}_{1}$ & 273.30 & 273.03 & 269.10 & 266.58 & 266.53 & 263.38 & 262.10 & 261.05 & 257.56 \\
\hline & $E_{1}$ & 0.1878 & 0.1904 & 0.2262 & 0.2502 & 0.2689 & 0.2794 & 0.2912 & 0.3004 & 0.3313 \\
\hline & $p_{2}$ & 10.003 & 10.023 & 10.336 & 10.565 & $10.766^{*}$ & 10.885 & 11.026 & 11.146 & 11.583 \\
\hline & $\mathbb{U}_{2}$ & 273.29 & 273.03 & 269.09 & 266.58 & 264.54 & 263.39 & 262.10 & 261.06 & 259.57 \\
\hline & $E_{2}$ & 0.1670 & 0.1695 & 0.2051 & 0.2285 & 0.2470 & 0.2573 & 0.2690 & 0.2780 & 0.3084 \\
\hline \multirow{9}{*}{$N=20$} & $p_{0}$ & 5.6587 & 5.7769 & 5.9918 & 6.1528 & $6.2970^{*}$ & 6.3827 & 6.4864 & 6.5726 & 6.7395 \\
\hline & $\mathbb{U}_{0}$ & 256.57 & 251.83 & 244.26 & 239.33 & 235.35 & 233.16 & 230.66 & 228.70 & 225.17 \\
\hline & $E_{0}$ & 0.1888 & 0.2120 & 0.2487 & 0.2607 & 0.2918 & 0.3023 & 0.3143 & 0.3240 & 0.3405 \\
\hline & $p_{1}$ & 7.8493 & 8.0045 & 8.2883 & 8.4984 & $8.6862^{*}$ & 8.7982 & 8.9340 & 9.0436 & 9.2575 \\
\hline & $\mathbb{U}_{1}$ & 256.57 & 251.87 & 244.28 & 239.36 & 235.38 & 233.17 & 230.64 & 228.70 & 225.18 \\
\hline & $E_{1}$ & 0.1779 & 0.2010 & 0.2372 & 0.2726 & 0.2797 & 0.2902 & 0.3021 & 0.3113 & 0.3278 \\
\hline & $p_{2}$ & 10.003 & 10.195 & 10.539 & 10.792 & $11.017^{*}$ & 11.152 & 11.314 & 11.444 & 11.699 \\
\hline & $\mathbb{U}_{2}$ & 256.59 & 251.83 & 244.26 & 239.38 & 235.15 & 233.15 & 230.63 & 228.70 & 225.16 \\
\hline & $E_{2}$ & 0.1670 & 0.1899 & 0.2260 & 0.2493 & 0.2680 & 0.2785 & 0.2903 & 0.2993 & 0.3157 \\
\hline \multirow{9}{*}{$N=30$} & $\overline{p_{0}}$ & 5.6243 & 5.7769 & 5.9918 & 6.1528 & 6.2970* & 6.3827 & 6.4864 & 6.5726 & 6.6828 \\
\hline & $\mathbb{U}_{0}$ & 239.88 & 230.64 & 219.39 & 212.07 & 206.17 & 202.93 & 199.23 & 196.33 & 192.84 \\
\hline & $E_{1}$ & 0.1817 & 0.2120 & 0.2487 & 0.2726 & 0.2918 & 0.3023 & 0.3143 & 0.3236 & 0.3349 \\
\hline & $p_{1}$ & 7.8264 & 8.0305 & 8.3203 & 8.5365 & $8.7274^{*}$ & 8.8424 & 8.9784 & 9.0940 & 9.2397 \\
\hline & $\mathbb{U}_{1}$ & 239.87 & 230.70 & 219.40 & 212.05 & 206.19 & 202.91 & 199.25 & 196.31 & 192.81 \\
\hline & $E_{1}$ & 0.1744 & 0.2042 & 0.2409 & 0.2647 & 0.2836 & 0.2941 & 0.3059 & 0.3153 & 0.3265 \\
\hline & $p_{2}$ & 10.003 & 10.258 & 10.614 & 10.879 & $11.114^{*}$ & 11.255 & 11.420 & 11.562 & 11.737 \\
\hline & $\mathbb{U}_{2}$ & 239.89 & 230.65 & 219.42 & 212.09 & 206.21 & 202.92 & 199.27 & 196.31 & 192.84 \\
\hline & $E_{2}$ & 0.1670 & 0.1970 & 0.2332 & 0.2568 & 0.2756 & 0.2861 & 0.2977 & 0.3071 & 0.3181 \\
\hline \multirow{9}{*}{$N=40$} & $p_{0}$ & 5.6071 & 5.7769 & 5.9918 & 6.1528 & $6.2970^{*}$ & 6.3827 & 6.4864 & 6.5726 & 6.6559 \\
\hline & $\mathbb{U}_{0}$ & 223.20 & 209.44 & 194.52 & 184.81 & 177 & 172.70 & 167.80 & 163.97 & 160.44 \\
\hline & $E_{0}$ & 0.1780 & 0.2120 & 0.2487 & 0.2726 & 0.2918 & 0.3023 & 0.3143 & 0.3233 & 0.3323 \\
\hline & $p_{1}$ & 7.8149 & 8.0449 & 8.3378 & 8.5541 & $8.7481^{*}$ & 8.8660 & 9.0021 & 9.1208 & 9.2307 \\
\hline & $\mathbb{U}_{1}$ & 223.18 & 209.48 & 194.49 & 184.84 & 177.04 & 172.64 & 167.85 & 164.01 & 160.43 \\
\hline & $E_{1}$ & 0.1726 & 0.2062 & 0.2429 & 0.2665 & 0.2855 & 0.2962 & 0.3079 & 0.3172 & 0.3258 \\
\hline & $p_{2}$ & 10.003 & 10.29 & 10.655 & 10.926 & $11.167^{*}$ & 11.311 & 11.479 & 11.622 & 11.761 \\
\hline & $\mathbb{U}_{2}$ & 223.19 & 209.53 & 194.54 & 184.81 & 177 & 172.65 & 167.85 & 164.02 & 160.44 \\
\hline & $E_{2}$ & 0.1670 & 0.2005 & 0.2370 & 0.2607 & 0.2796 & 0.2901 & 0.3017 & 0.3109 & 0.3195 \\
\hline \multirow{9}{*}{$N=50$} & $p_{0}$ & 5.5956 & 5.7769 & 5.9918 & 6.1528 & $6.2970^{*}$ & 6.3827 & 6.4864 & 6.5726 & 6.6381 \\
\hline & $\mathbb{U}_{0}$ & 206.65 & 188.25 & 169.65 & 157.56 & 147.82 & 142.47 & 136.37 & 131.60 & 128.14 \\
\hline & $E_{0}$ & 0.1775 & 0.2141 & 0.2510 & 0.2750 & 0.2944 & 0.3048 & 0.3166 & 0.3262 & 0.3304 \\
\hline & $p_{1}$ & 7.8064 & 8.0507 & 8.3466 & 8.56 & $8.7657^{*}$ & 8.8779 & 9.0199 & 9.1356 & 9.2218 \\
\hline & $\mathbb{U}_{1}$ & 206.58 & 188.46 & 169.68 & 157.57 & 147.79 & 142.48 & 136.31 & 131.59 & 128.19 \\
\hline & $E_{1}$ & 0.1712 & 0.2082 & 0.2453 & 0.2689 & 0.2880 & 0.2986 & 0.3103 & 0.3197 & 0.3252 \\
\hline & $p_{2}$ & 10 & 10.31 & 10.681 & 10.955 & 11.199* & 11.343 & 11.518 & 11.663 & 11.773 \\
\hline & $\mathbb{U}_{2}$ & 206.67 & 188.37 & 169.62 & 157.51 & 147.81 & 142.47 & 136.38 & 131.57 & 128.12 \\
\hline & $E_{2}$ & 0.1667 & 0.2026 & 0.2394 & 0.2633 & 0.2820 & 0.2924 & 0.3042 & 0.3135 & 0.3202 \\
\hline
\end{tabular}

Table 4. Equilibrium prices, expected compensated utilities and expected acceptance rates for different number of users $N$ 


\begin{tabular}{|l|l|l|l|}
\hline & & $p_{0_{\max }^{*}}^{*}$ & $p_{1_{\max }^{*}}^{*}$ \\
\hline \multirow{4}{*}{$\begin{array}{c}* \\
c\end{array}=5$} & $c 2=1$ & 6.5428 & 9.0792 \\
\cline { 2 - 4 } & $c 2=3$ & 6.6559 & 9.2307 \\
\cline { 2 - 4 } & $c 2=9$ & 6.6232 & 9.1861 \\
\cline { 2 - 4 } & $c 2=13$ & 6.5964 & 9.1534 \\
\cline { 2 - 4 } & $c 2=20$ & 6.5815 & 9.1297 \\
\hline
\end{tabular}

Table 5. Maximum equilibrium prices of $\mathrm{WSP}_{0}$ and $\mathrm{WSP}_{1}\left(p_{0}^{\prime *}, p_{1}^{\prime *}\right)$ for three-WSP scenario with various cost of $\mathrm{WSP}_{2}$.

of $\mathrm{WSP}_{0}$ and $\mathrm{WSP}_{1}$ are kept unchanged while $\mathrm{WSP}_{2}$ 's cost varies, was conducted. Fig. 10 presents the equilibrium prices $\left(p_{0}^{\prime *}, p_{1}^{\prime *}\right)$ with $\mathrm{WSP}_{2}$ taking different costs. For ease of illustration, the maximum equilibrium prices corresponding to Fig. 10 (a), (b) and (c) are listed in Table 5. It can be observed that when $\mathrm{WSP}_{2}$ 's cost is lower than costs of $\mathrm{WSP}_{0}$ and $\mathrm{WSP}_{1}$, in equilibrium, the maximum prices that $\mathrm{WSP}_{0}$ and $\mathrm{WSP}_{1}$ could reach are lower compared to the case where $\mathrm{WSP}_{2}{ }^{\prime}$ cost is higher than the costs of $\mathrm{WSP}_{0}$ and $\mathrm{WSP}_{1}$. For the latter case, the entry of a new WSP with a higher cost results in slight lower maximum equilibrium prices for both $\mathrm{WSP}_{0}$ and $\mathrm{WSP}_{1}$.

\section{Advanced thoughts}

The presented material can be usefully extended in a number of ways. In this section only the extensions will be identified and potential game theory modeling modes indicated.

Firstly an assumption in the section on the basic wireless duopoly was that all users show the same basic behavior. Relaxing this, a competition between the WSPs and a set of N types of users can be described. The $\mathrm{N}$ types of users could describe economic, social or regulatory groupings that have differing QoS and price utility definitions. This would allow for the development of a scaled preference analysis that could be used to gauge more accurately
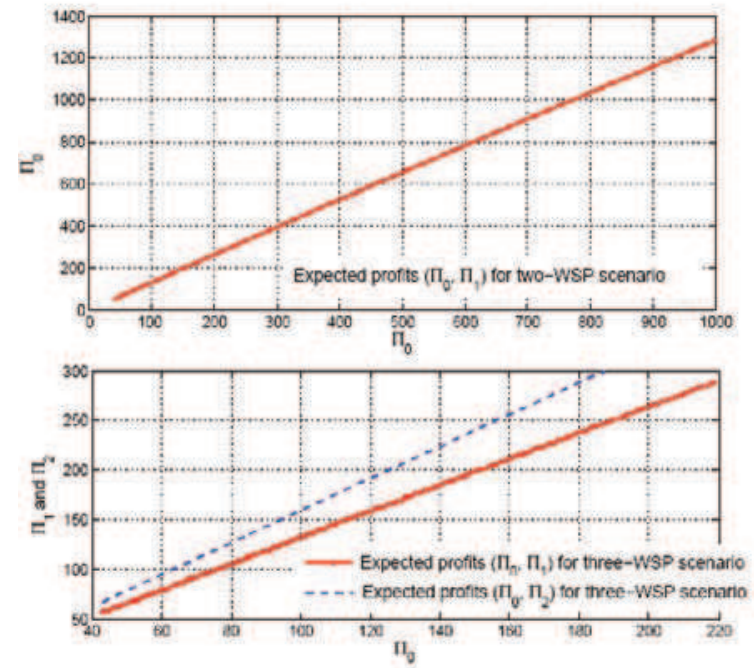

Fig. 9. Expected profits associated with equilibrium prices in Fig. 8 

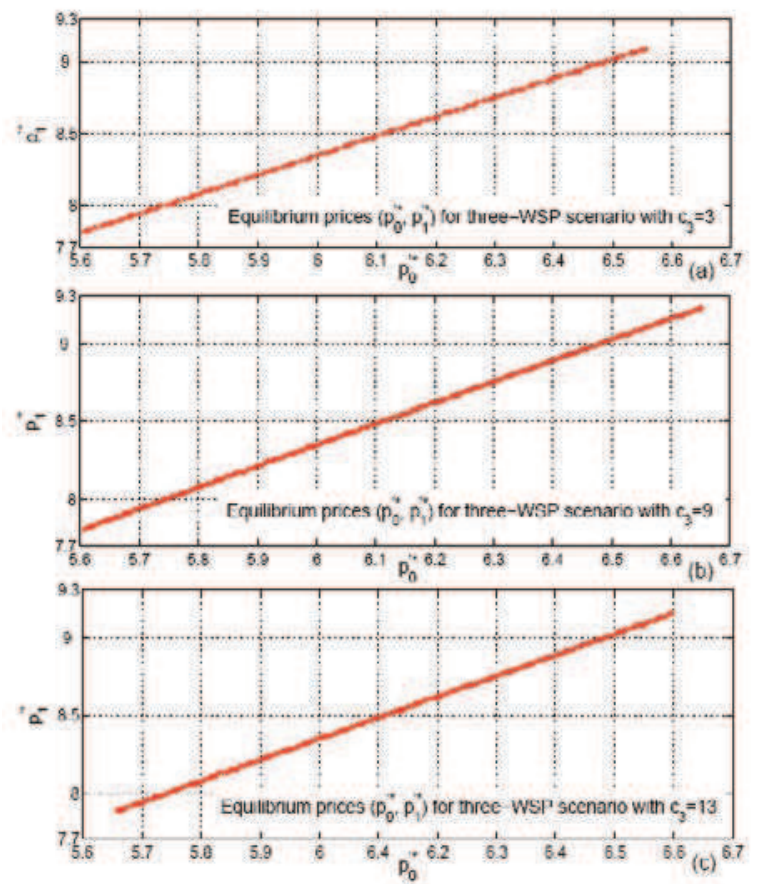

Fig. 10. Equilibrium prices of $\mathrm{WSP}_{0}$ and $\mathrm{WSP}_{1}\left(p_{0}^{\prime *}, p_{1}^{\prime *}\right)$ for three-WSP scenario with various cost of $\mathrm{WSP}_{2}$.

the social benefits of regulated access to the wireless bandwidth. Secondly the analysis of oligopoly based pricing depends on the assumption of a mature market where entrances and exits by WSPs are not relevant. In actual fact this is quite unrealistic and can profitably be expanded to take into account changes in the number of WSPs during a period and the impact on both relative profit and market share. Finally by changing the analysis basis queue to a more dynamic queue with memory effect models of user churn and brand loyalty can be developed that could show the benefit of branding compaigns.

\section{References}

Altman, E., Barman, D. \& Azouzi, R. E. (2006). Pricing Differentiated Services: A Game-Theoretic Approach, Computer Networks 50: 982-1002.

Altman, E. \& Basar, T. (1998). Multiuser Rate-Based Flow Control, IEEE Transactions on Communication 46: 940-949.

Altman, E. \& Wynter, L. (2002). Equilibrium, Games and Pricing in Transportation and Telecommunication Networks, Technical Report 4632, IRISA .

Armony, M. \& Haviv, M. (2003). Price and Delay competition Between Two Service Providers, European Journal of Operational Research 147: 32-50.

Basar, T. \& Srikant, R. (2002). Revenue-maximizing Pricing and Capacity Expansion in a Many-user Regime, Proceedings of the 21st Annual Joint Conference of the IEEE Computer and Communications Societies (IEEE INFOCOM 2002), New York, USA. 
Cao, X., Shen, H., Milito, R. \& Wirth, P. (2002). Internet Pricing with a Game Theoretical Approach: Concepts and Examples, IEEE/ACM Transactions on Networking 10: 208-216.

Das, S. K., Chatterjee, M. \& Lin, H. (2004). An Econometric Model for Resource Management in Competitive Wireless Data Networks, IEEE Network Magazine 18(6): 20-26.

Dziong, Z. \& Mason, L. (1996). Fair-efficient Call Admission Control Policies for Broadband Network - A Game Theoretical Approach, IEEE/ACM Transactions on Networking 4: 123-136.

Gibbens, R., Mason, R. \& Steinberg, R. (2000). Internet Service Classes under Competition, IEEE Journal on Selected Areas in Communications 18(7): 2490-2498.

Hock, N. C. (1996). Queuing Modeling Fundamentals, John Wiley and Sons Ltd.

Jagannatha, S., Nayak, J., Almeroth, K. \& Hofmann, M. (2002). A Model for Discovering Customer Value for E-content, Proceedings of the Eighth ACM SIGKDD International Conference on Knowledge Discovery and Data Mining, Edmonton, Alberta, Canada, pp. 23-26.

Kao, Y. \& Huan, J. (2008). Price-based Resource Allocation for Wireless Ad Hoc Networks with Multi-rate Capability and Energy Constraints , Computer Communications 31: 3613-3624.

Kelly, F. P. (2000). Models for A Self-Managed Internet, Philosophical Transactions of the Royal Society A358: 2335-2348.

Kelly, F. P., Mauloo, A. K. \& Tan, D. K. H. (1998). Rate Control in Communication Networks: Shadow Prices, Proportional Fairness and Stability, Journal of the Operational Research Society 49: 237-252.

Khan, S. Q. (2005). Optimizing Providers' Profit in Per Networks Applying Automatic Pricing and Game Theory, PhD thesis, The University of Kansas .

La, R. J. \& Anantharam, V. (1999). Network Pricing using Game Theoretic Approach, Proceedings of 38th IEEE Conference on Decision and Control, Vol. 4, Phoenix, AZ Piscataway, NJ, pp. 4008-4013.

La, R. J. \& Anantharam, V. (2002). Utility-based Rate Control in the Internet for Elastic Traffic, IEEE/ACM Transactions on Networking 10(2): 272-286.

Lam, R. K., Chiu, D. \& Lui, J. C. S. (2007). On the Access Pricing and Network Scaling Issues of Wireless Mesh Networks, IEEE transactions on Computers 56: 1456-1469.

Lam, R. K., Lui, J. C. S. \& Chiu, D. (2006). On the Access Pricing Issues of Wireless Mesh Networks, Proceedings of the 26th IEEE International Conference on Distributed Computing Systems (ICDCS 2006), Lisboa, Portugal.

Low, S. H. \& Lapsley, D. E. (1999). Optimization Flow Control: Basic Algorithm and Convergence, IEEE/ACM Transactions on Networking 7(6): 861-874.

Lüthi, M., Nadjm-Tehrani, S. \& Curescu, C. (2006). Comparative Study of Price-based Resource Allocation Algorithms for Ad Hoc Networks, Proceedings of the 20th International Parallel and Distributed Processing Symposium (IPDPS 2006), Rhodes Island, Greece.

M. Bouhtou, M. D. \& Wynter, L. (2003). Capacitated Network Revenue Management through Shadow Pricing, Networked Group Communication 2816: 342-351.

Mandjes, M. (2003). Pricing Strategies under Heterogeneous Service Requirements, Computer Networks 42(2): 231-249.

Musacchio, J. \& Walrand, J. (2006). WiFi Access Point Pricing as a Dynamic Game, IEEE/ACM Transactions on Networking 14: 289-301. 
Parsons, S., Gmytrasiewicz, P. J. \& Wooldridge, M. J. (2002). Game Theory and Decision Theory in Agent-Based Systems, Kluwer Academic Publishers.

Qiu, Y. \& Marbach, P. (2003). Bandwith Allocation in Ad-Hoc Networks: A Price-Based Approach, Proceedings of the 22nd Annual Joint Conference of the IEEE Computer and Communications Societies (IEEE INFOCOM 2003), Vol. 2, San Francisco, California, USA, pp. 797-807.

Ros, D. \& Tuffin, B. (2004). A Mathematical Model of the Paris Metro Pricing Scheme for Charging Packet Network, Computer Networks 46: 73-85.

Sakurai, H., Kasahara, S. \& Adachi, N. (2003). Internet Pricing and User Opt-out Strategy under two ISPs Competition, IEICE Technical Report (Institute of Electronics, Information and Communication Engineers) 102(694(IN2002 233-305)): 153-156.

Shu, J. \& Varaiya, P. (2003). Pricing Network Services, Proceedings of the 22nd Annual Joint Conference of the IEEE Computer and Communications Societies (IEEE INFOCOM 2003), San Franciso, CA, USA.

Tassiulas, L., Kar, K. \& Sarkar, S. (2001). A Simple Rate Control Algorithm for Maximizing Total User Utility, Proceedings of the 20th Annual Joint Conference of the IEEE Computer and Communications Societies (IEEE INFOCOM 2001), Vol. 1, Anchorage, Alaska, USA, pp. 133-141.

Wang, X. \& Schulzrinne, H. (1999). RNAP: A Resource Negotiation and Pricing Protocol, Proceedings of International Workshop on Network and Operating System Support for Digital Audio and Video (NOSSDAV'99), Basking Ridge, New Jersey, pp. 77-93.

Xue, Y., Li, B. \& Nahrstedt, K. (2003). Price-based Resource Allocation in Wireless Ad Hoc Networks, Proceedings of the 11th International Conference on Quality of Service (IWQoS 2003), Berkeley, CA, USA.

Xue, Y., Li, B. \& Nahrstedt, K. (2006). Optimal Resource Allocation in Wireless Ad Hoc Networks: A Price-Based Approach, IEEE transactions on mobile computing 5: 347-364.

Yaïche, H., Mazumdar, R. R. \& Rosenberg, C. (2000). A Game Theoretic Framework for Bandwidth Allocation and Pricing in Broadband Networks, IEEE/ACM Transactions on Networking 8: 667-678.

Zemlianov, A. \& de Veciana, G. (2005). Cooperation and Decision-Making in a Wireless Multi-Provider Setting, Proceedings of 24th Annual Joint Conference of the IEEE Computer and Communications Societies (IEEE INFOCOM 2005), Miami, FL, USA.

Zhang, Z., Dey, D. \& Tan, Y. (2008). Price and QoS Competition in Data Communication Services, European Journal of Operational Research 187: 871-886.

Zhu, H., Nel, A. \& Clarke, W. (2009). A Duopoly Pricing Model for Wireless Mesh Networks under Congestion-sensitive Users, South African Institute of Electrical Engineers Africa Research Journal 100: 48-58. 


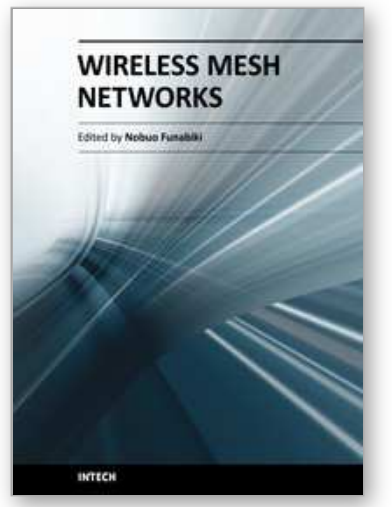

\author{
Wireless Mesh Networks \\ Edited by Nobuo Funabiki
}

ISBN 978-953-307-519-8

Hard cover, 308 pages

Publisher InTech

Published online 14, January, 2011

Published in print edition January, 2011

The rapid advancements of low-cost small-size devices for wireless communications with their international standards and broadband backbone networks using optical fibers accelerate the deployment of wireless networks around the world.â€"The wireless mesh network has emerged as the generalization of the conventional wireless network. However, wireless mesh network has several problems to be solved before being deployed as the fundamental network infrastructure for daily use. The book is edited to specify some problems that come from the disadvantages in wireless mesh network and give their solutions with challenges. The contents of this book consist of two parts: Part I covers the fundamental technical issues in wireless mesh network, and Part II the administrative technical issues in wireless mesh network. This book can be useful as a reference for researchers, engineers, students and educators who have some backgrounds in computer networks, and who have interest in wireless mesh network. It is a collective work of excellent contributions by experts in wireless mesh network.

\title{
How to reference
}

In order to correctly reference this scholarly work, feel free to copy and paste the following:

Andre Nel and Hailing Zhu (2011). Wireless Service Pricing under Multiple Competitive Providers and Congestion-Sensitive Users, Wireless Mesh Networks, Nobuo Funabiki (Ed.), ISBN: 978-953-307-519-8, InTech, Available from: http://www.intechopen.com/books/wireless-mesh-networks/wireless-service-pricingunder-multiple-competitive-providers-and-congestion-sensitive-users

\section{INTECH}

open science | open minds

\section{InTech Europe}

University Campus STeP Ri

Slavka Krautzeka 83/A

51000 Rijeka, Croatia

Phone: +385 (51) 770447

Fax: +385 (51) 686166

www.intechopen.com

\section{InTech China}

Unit 405, Office Block, Hotel Equatorial Shanghai

No.65, Yan An Road (West), Shanghai, 200040, China

中国上海市延安西路65号上海国际贵都大饭店办公楼405单元

Phone: +86-21-62489820

Fax: $+86-21-62489821$ 
(C) 2011 The Author(s). Licensee IntechOpen. This chapter is distributed under the terms of the Creative Commons Attribution-NonCommercialShareAlike-3.0 License, which permits use, distribution and reproduction for non-commercial purposes, provided the original is properly cited and derivative works building on this content are distributed under the same license. 